\title{
Padrão morfológico e ciclo de vida de Eutetranychus banksi (Acari: Tetranychidae) de diferentes locais e hospedeiros
}

\author{
Viviane M. Mattos ${ }^{1} \&$ Reinaldo J. F. Feres ${ }^{2}$ \\ 1 Universidade de Cuiabá, Campus de Primavera do Leste. Avenida Guterrez 241, Jardim Riva, 78850-000 Primavera do \\ Leste, Mato Grosso, Brasil. E-mail: vivianemmattos@yahoo.com.br \\ 2 Laboratório de Acarologia, Departamento de Zoologia e Botânica, Universidade Estadual Paulista. Rua Cristóvão Colombo \\ 2265, Jardim Nazareth, 15054-000 São José do Rio Preto, São Paulo, Brasil. E-mail: reinaldo@ibilce.unesp.br
}

\begin{abstract}
Morphological pattern and life cycle of Eutetranychus banksi (Acari: Tetranychidae) from different localities and hosts. Eutetranychus banksi (McGregor, 1914) is a phytophagous, polyphagous and cosmopolitan species recorded on 23 plant families in 24 countries in North, Central and South Americas, Europe, Asia, and Africa. Specimens of $E$. banksi present morphological variability among individuals of the same population and also among populations from different host species, being commonly referred to as a polytypic species, despite the fact that studies based on meristic comparisons of these populations are lacking. Also, there is no data available in the literature on the biological life tables of $E$. banksi on different hosts. Specimens collected in Brazil, Guadeloupe, Martinique, Mexico, and Paraguay were investigated in order to recognize morphological patterns among populations from different localities and hosts. A redescription of the species is provided based on data both from literature and new observations. Also, the biological cycle on three hosts, experiments of hosts exchange and the possibility of interbreeding in individuals originating from different populations were evaluated. Significant differences in the morphology of the females of different populations were detected when comparing the different hosts. The length of the dorsal pairs of setae v2, sc2, c1, c3, e1 and $h 1$ differentiated the specimens of the populations collected from Citrus sp. from those of Hevea brasiliensis Muell. Arg. and Pachira aquatica Aubl.. Herein we observed significant variation among the life cycle of this species on the three hosts studied. When a substrate different from the one where the mites were collected was used for the biological cycle essay, significant variation was observed in several parameters such as average oviposition rate, events of arrenothoky, and sex ratio. Interbreeding with populations collected from Citrus sinensis and P. aquatica resulted in no descendants, although mating was observed.
\end{abstract}

KEY WORDS. Arrenothoky; Citrus sinensis; Hevea brasiliensis; interbreeding; multivariate morphometry.

Eutetranychus banksi (McGregor, 1914) ocorre, com ampla distribuição geográfica, nas três Américas (Jeppson et al. 1975, Bolland et al. 1998), Europa, Ásia e África (BAKER \& TutTle 1994) sendo registrada sobre uma grande variedade de hospedeiros, aproximadamente 90 espécies vegetais de 23 famílias (Migeon \& DoRKeld 2006). Sua importância econômica como praga é reconhecida nos cultivos de citros no Texas (DeAn 1980) e na Flórida (Muma et al. 1953). No Brasil, E. banksi (referido vulgarmente como "ácaro-texano") está associado aos citros e a uma variedade de outros hospedeiros cultivados e silvestres (Flechtmann \& Abreu 1973, Gondim Jr \& Oliveira 2001, Feres et al. 2002, Bellini et al. 2005, Moraes \& FleChTMAnN 2008), embora ainda não tenha sido apontado no país como causador de danos à agricultura. Apesar de tratar-se de uma espécie neotropical, sua origem geográfica precisa é desconhecida (Bolland et al. 1998) e sua dispersão pode ter sido amplificada através do cultivo dos citros e plantas ornamentais (PRITCHARD \& BAKER 1955), demonstrando a grande capacidade de adaptação de E. banksi a diferentes hospedeiros, dentre eles espécies nativas brasileiras como a seringueira, Hevea brasiliensis Muell. Arg., e a monguba, Pachira aquatica Aubl. (Bolland et al. 1998). Existem estudos biológicos da espécie demonstrando a capacidade de sobrevivência sob temperaturas entre $15^{\circ}$ e $32^{\circ} \mathrm{C}$ (Childers et al. 1991) e em utilizar outros hospedeiros além daquele no qual a população foi originalmente obtida. Espécimes coletados sobre mamão (Carica papaya Linnaeus) puderam ser criados satisfatoriamente tanto sobre mamão quanto sobre dois cultivares de acerola (Malpighia emarginata A. DC.) e laranja lima (Citrus sp.) (BARBosa et al. 2004). Contudo, considerando a ampla distribuição geográfica, o número de espécies vegetais nas quais foi registrada e a capacidade adaptativa da espécie, mais estudos são necessários para elucidar o potencial biológico da espécie.

Eutetranychus banksi apresenta variações morfológicas entre diferentes populações e hospedeiros, além de variações

(c) 2009 Sociedade Brasileira de Zoologia | www.sbzoologia.org.br | All rights reserved. 
dentro da mesma população, em relação ao comprimento e forma das setas dorsais (Muma et al. 1953, Pritchard \& BAKer 1955, Flechtmann \& Baker 1975). Pritchard \& Baker (1955) e FleChTMANN \& BAKER (1975), por exemplo, apresentam ilustrações das tíbias e tarsos das pernas I e II de fêmeas que diferem no número de setas táteis e quimiossensoriais representados. $\mathrm{O}$ polimorfismo presente em E. banksi levou pesquisadores a considerarem-na uma espécie politípica (Pritchard \& BAKER 1955).

Raças em diferentes hospedeiros têm sido documentadas em organismos parasitos e fitófagos (BERLOCHER \& FEDER 2002, Funk et al. 2002) e podem se formar em espécies generalistas com relativo isolamento de populações especializadas em diferentes espécies hospedeiras ou em espécies especialistas em uma espécie hospedeira, como resultado do isolamento em diferentes indivíduos hospedeiros. Isso pode resultar numa restrição do fluxo gênico entre as populações nos diferentes hospedeiros mesmo em condições de ocorrência simpátrica (e.g., FILCHAK et al. 2000, Groman \& Pellmyr 2000). De acordo com Helle \& Overmeer (1973), a abundância das raças em Acari é uma conseqüência do sistema de reprodução haplodiplóide, que diminui a variabilidade genética intra-populacional e ao mesmo tempo aumenta a diferença entre as populações.

Os métodos morfométricos podem ser usados para detectar diferenças sutis entre populações (REyment et al. 1981). Para distinguir as variações entre os grupos utiliza-se a Análise das Variáveis Canônicas (AVC). Essa análise fornece uma descrição das diferenças entre os grupos especificados a priori em um conjunto de dados multivariados, maximizando a variação entre os grupos relativa à variação dentro dos grupos (MONTEIRO \& ReIs 1999).

Embora alguns cuidados devam ser considerados ao se comparar as dimensões corporais de ácaros submetidos a diferentes períodos de montagem em meio de Hoyer (ReEse et al. 1996), o uso da morfometria na Acarologia mostra-se como um instrumento útil de caracterização morfológica e sistemática de espécies, sendo que estudos sobre variação morfológica de ácaros fitófagos associada a hospedeiros são necessários para elucidar a interação ácaro-hospedeiro e melhorar a sistemática no nível de espécie (SKORACKa et al. 2002).

No presente trabalho, tivemos como objetivo analisar a variação morfológica de fêmeas de E. banksi de diferentes populações e hospedeiros, buscando verificar a existência de possíveis padrões morfológicos e o ciclo de vida de indivíduos pertencentes a populações de três hospedeiros, em hospedeiros trocados e com cruzamento entre indivíduos de diferentes populações.

\section{MATERIAL E MÉTODOS}

Foram utilizados exemplares fêmeas depositados nas coleções de Acari da Universidade Estadual Paulista, São José do Rio Preto (DZSJRP); Setor de Zoologia Agrícola, Escola Superior de Agricultura Luiz de Quieroz, (ESALQ/USP), Piracicaba; e coleção particular do Dr Carlos H.W. Flechtmann (ESALQ/USP), originários do Brasil (Pernambuco e São Paulo), Guadalupe, Martinica, México e Paraguai (Tab. I). Além disso, foram criados em laboratório e montados em lâminas de microscopia com meio de Hoyer (Flechtmann 1975) exemplares provenientes dos seguintes hospedeiros: Pachira aquatica Aubl. (Malvaceae), dos municípios de Bálsamo e São José do Rio Preto; Hevea brasiliensis Muell. Arg. (Euphorbiaceae) de Cedral e São José do Rio Preto; Citrus sp. (Rutaceae) de São José do Rio Preto e Guapiara, São Paulo. Para os estudos de morfometria, os ácaros oriundos de citros não tiveram seus hospedeiros identificados ao nível específico, no entanto, para análise biológica foram utilizados indivíduos de apenas uma população oriunda de Citrus sinensis. As medições foram feitas com auxílio de microscópio fotônico com contraste de fases e retículo calibrado para as objetivas utilizadas. A terminologia utilizada para as setas dorsais é aquela proposta por GRANDJEAN (1939) de acordo com LiNDQUIST (1985). Todas as medidas são apresentadas em micrômetros $(\mu \mathrm{m})$. Os caracteres analisados foram: o comprimento do idiossoma (CI); largura do idiossoma ( $L I)$; comprimento dos pares de setas dorsais $(v 2, s c 1, s c 2, c 1, c 2, c 3, d 1, d 2, e 1, e 2, f 1, f 2, h 1)$ e distância de inserção entre os elementos dos pares $s c 2-c 3, c 1-c 1, c 1$ $c 2, c 2-c 3, c 1-d 1, d 1-d 1, d 1-d 2, d 1-e 1, e 1-e 1, e 1-e 2, e 2-f 1, f 1-f 1$. Os resultados foram submetidos à análise de morfometria univariada através da análise de box plot medianas e quartis com o auxílio do software Bioestat ${ }^{\circledR}$ 4.0, e multivariada com a análise das variáveis canônicas (AVC) com o auxílio do software $\mathrm{SAS}^{\circledR}$ 9.1.3. Os testes multivariados aplicados à análise das variáveis canônicas foram: Wilks' Lambda, Pillai's Trace, HotellingLawley Trace e Roy's Greatest Root, usualmente empregados no programa $\mathrm{SAS}^{\circledR}$. Para a análise de morfometria multivariada, as populações foram comparadas entre si de acordo com o hospedeiro e localidade. Foram agrupadas na análise populações de um mesmo hospedeiro de diferentes localidades para avaliação da variabilidade biogeográfica e populações de diferentes hospedeiros da mesma localidade para avaliação da variabilidade entre hospedeiros. Todos os caracteres (tamanho e distância entre setas) não foram reunidos numa única análise devido à restrição material imposta pelo tempo de preservação diferente dos espécimes, o que poderia prejudicar os resultados (Reese et al. 1996). Foi analisado também o número e o tipo de setas presentes nos artículos (da coxa ao tarso) das pernas I a IV. O material testemunho, espécimes montados em lâminas (números 6500 a 6801) e imagens capturadas para o estudo, foi depositado na coleção de Acari (DZSJRP), Departamento de Zoologia e Botânica, IBILCE, Universidade Estadual Paulista (http:www.splink.cria.org.br) e respectivo banco de imagens.

Foram analisadas, isolada e conjuntamente, 248 fêmeas oriundas dos hospedeiros $H$. brasiliensis (91), Citrus sp. (78) e $P$. aquatica (79). Estas foram coletadas em duas localidades para cada hospedeiro, de modo que 30 fêmeas foram medidas para cada localidade/hospedeiro. Na análise conjunta foram utilizadas as medidas de 180 fêmeas oriundas destes hospedeiros. Na análise isolada foram reunidas todas as fêmeas disponíveis 
oriundas de cada hospedeiro nas diferentes localidades (Tab. I). Para avaliar a variação entre hospedeiros, foram analisadas conjuntamente 52 fêmeas oriundas de 11 hospedeiros de diferentes localidades (Tab. I e Fig. 20).

A partir dos novos dados morfológicos e biológicos obtidos, confrontados com aqueles da descrição original (MACGregor 1914: 357-358) e disponíveis na literatura, elaboramos uma redescrição da espécie. As medidas informadas para o tamanho do idiossoma e setas dorsais, representam a média aritmética dos 250 exemplares fêmeas e 50 machos seguidas, entre parênteses, dos valores mínimos e máximos encontrados para as mesmas.

Indivíduos coletados no município de São José do Rio Preto sobre $H$. brasiliensis, $C$. sinensis e $P$. aquatica foram criados nas folhas de seus respectivos hospedeiros. A criação foi mantida em câmara do tipo BOD a $28 \pm 1^{\circ} \mathrm{C}, 12$ horas de fotofase e $70 \pm$ $10 \%$ UR. Fêmeas e machos foram transferidos com pincel de pêlos finos para unidades de criação. As unidades foram confeccionadas com folhas ou folíolos dos três hospedeiros lavadas em água destilada e colocadas com a face abaxial sobre um pedaço de esponja de náilon umedecido mantido em bandeja de plástico de $6 \times 15 \times 23 \mathrm{~cm}$. As bordas das folhas e folíolos foram recobertas com tiras de algodão hidrófilo. Diariamente, foi adicionada água destilada às bandejas para manter a umidade do sistema. Os ácaros foram transferidos para novas unidades de criação quando as folhas começavam a apresentar danos (clorose ou necrose dos tecidos). O experimento foi realizado em três blocos com 60 fêmeas, 20 em cada tratamento, provenientes da mesma população de cada um dos três hospedeiros e criadas nos três substratos sendo: bloco 1 - fêmeas provenientes de $H$. brasiliensis, em folhas/folíolos de $H$. brasiliensis, $P$. aquatica e $C$. sinensis; bloco 2 - fêmeas provenientes de C. sinensis, em folhas/ folíolos de $C$. sinensis, $P$. aquatica e $H$. brasiliensis; bloco 3 - fêmeas provenientes de $P$. aquatica, em folhas/folíolos de $P$. aquatica, $H$. brasiliensis e $C$. sinensis. Foram montadas unidades semelhantes às da criação estoque, delimitando-se arenas de $2,5 \mathrm{~cm}^{2} \mathrm{com}$ tiras de lenço de papel para confinamento dos indivíduos e acompanhamento do desenvolvimento de todas as fases. No início do experimento, fêmeas foram transferidas para arenas individuais e retiradas após a oviposição, mantendo-se apenas um ovo

Tabela I. Relação do número de fêmeas de E. banksi analisadas oriundas de 13 hospedeiros.

\begin{tabular}{|c|c|c|c|c|}
\hline Hospedeiro & Local & Estado & País & Fêmeas \\
\hline Acacia sp. & Recife & Pernambuco & Brasil & 10 \\
\hline Bauhinia sp. & São José do Rio Preto & São Paulo & Brasil & 5 \\
\hline \multirow[t]{5}{*}{ Citrus sp. } & Baillif & Basse-Terre & Guadalupe & 3 \\
\hline & Capitán Bado & Amambay & Paraguai & 2 \\
\hline & Guapiara & São Paulo & Brasil & 30 \\
\hline & Recife & Pernambuco & Brasil & 13 \\
\hline & São José do Rio Preto & São Paulo & Brasil & 30 \\
\hline Codiaeum variegatum & Terre-de-Haut & Les Saints & Guadalupe & 1 \\
\hline Erythrina sp. & Terre-de-Haut & Les Saints & Guadalupe & 2 \\
\hline Euphorbia heterophylla & Cedral & São Paulo & Brasil & 5 \\
\hline \multirow[t]{5}{*}{ Hevea brasiliensis } & Cedral & São Paulo & Brasil & 30 \\
\hline & Ibitinga & São Paulo & Brasil & 5 \\
\hline & Pindorama & São Paulo & Brasil & 9 \\
\hline & Piracicaba & São Paulo & Brasil & 17 \\
\hline & São José do Rio Preto & São Paulo & Brasil & 30 \\
\hline \multirow[t]{3}{*}{ Pachira aquatica } & Bálsamo & São Paulo & Brasil & 30 \\
\hline & Ilha Solteira & São Paulo & Brasil & 19 \\
\hline & São José do Rio Preto & São Paulo & Brasil & 30 \\
\hline Pachystachys lutea & Monterrey & Nuevo Leon & México & 1 \\
\hline Prunus persica & Monterrey & Nuevo Leon & México & 5 \\
\hline Ricinus communis & Case-Pilote & Distrito Saint-Pierre & Martinica & 2 \\
\hline Sargentia sp. & Monterrey & Nuevo Leon & México & 3 \\
\hline Thespesia populnea & Case-Pilote & Distrito Saint-Pierre & Martinica & 5 \\
\hline
\end{tabular}


por arena. Quando atingiram o estágio deutoninfal, as fêmeas receberam em suas arenas machos da criação estoque da mesma população.

Além disso, machos de dois diferentes hospedeiros foram transferidos para arenas de folha/folíolo do hospedeiro de origem das fêmeas que produziram as deutocrisálidas fêmeas nelas presentes. Foram observadas a oviposição, emergência das larvas e desenvolvimento até a fase adulta da geração F1 com determinação da razão sexual da prole. Em seguida foram feitos cruzamentos para testar a viabilidade reprodutiva da geração F2. O experimento foi realizado em dois blocos (de machos e fêmeas) com 45 indivíduos cada. Cada bloco foi dividido em três tratamentos com 15 indivíduos cada, sendo os tratamentos constituídos pelos três hospedeiros.

Nos dois experimentos, as observações foram feitas às 8:00, 13:00 e 18:00 h. Os resultados foram submetidos à análise de variância e as médias comparadas pelo teste de Tukey com utilização do software BioEstat 4.0.

\section{RESULTADOS}

\section{Redescrição de Eutetranychus banksi}

Fêmea. Medidas ( $\mathrm{n}=250)$ - comprimento do idiossoma (incluindo o rostro): 390 (145-462) mm; Largura: 288 (105-373) mm. Idiossoma robusto, deprimido, com coloração verde a marrom-pálida em vida. Manchas escuras laterais relativas ao conteúdo dos cecos digestivos são visíveis através da parede translúcida do corpo. Pernas translúcidas na região proximal e com coloração vermelho-ferrugem ao laranja nos artículos dos palpos e distais das pernas. No material tipo, descrito de mamona e mucuna, a coloração é relatada como sendo "rustyred". Fêmeas coletadas sobre Citrus sinensis apresentaram coloração avermelhada nos palpos e artículos distais das pernas mais pronunciada em relação a daquelas coletadas sobre $H$. brasiliensis e $P$. aquatica. Neste último hospedeiro, apresentou-se mais pálida o que sugere que a coloração sofreu interferência dos componentes alimentares disponíveis em cada diferente substrato. Nos espécimes vivos a posição de repouso, com as pernas I e II orientadas à frente do corpo e III e IV para trás, é característica. Os ovos são redondos, achatados e depositados preferencialmente ao longo da nervura central na face adaxial das folhas. É registrada sobre muitas espécies hospedeiras, preferencialmente na face adaxial das folhas ou folíolos. Contudo, observamos que ocupa preferencialmente a face abaxial das folhas em Cecropia sp. Dorso: A estriação é pouco conspícua, formando linhas suaves transversais na região mediana em relação ao eixo longitudinal do corpo, limitadas pelas inserções dos elementos dos pares de setas $c 1$ e $d 1$. Dessa forma, pode-se observar estriação transversal apenas na região histerossomal central. Às margens desta, a partir de uma constrição entre os elementos das setas $c 1$ e $d 1$, as linhas inicialmente próximas tornamse curvas e centrífugas seguindo em direção, correspondente na região ventral, à da inserção das coxas III e IV. Imediatamente abaixo da inserção dos elementos do par d1, e tendo essas como base, formam um triângulo com vértice mediano à inserção dos elementos do par $e 1$. Esse ponto coincide, em relação à região ventral, com a área estriada da abertura genital. Na região histerossomal estão localizados os elementos do par de poros $i a$, conspícuos e localizados na região mediana entre as bases dos elementos das setas $c 2$ e $d 2$, exatamente sobre uma linha imaginária entre as coxas III e IV. Os poros im e ip são menores e não conspícuos sob aumento de 400x, localizados entre a inserção dos elementos das setas $d 2-e 2$ e $e 2-f 2$, respectivamente. Setas dorsais curtas e espatuladas, pares v2 44 (1657), sc2 43 (18-54), c3 42 (17-57), d2 26 (10-46), e2 33 (13-52), $f 141$ (17-60), f2 28 (11-41) e $h 132$ (12-44), com a extremidade distal dilatada e espatulada ou em forma de clava, sempre maiores que as setas dos pares sc1 20 (6-38), c1 13 (5-19), sc2 16 (535), d1 14 (5-19), e116 (6-24), que são curtas e com formato de clava. Os pontos de inserção dos elementos dos pares de setas e1 e $f 1$ formam a figura de um trapézio invertido. Pernas: quetotaxia (da coxa ao tarso) - I: 2-1-6 [ou 7]-4-9(1)-13(1) + 1 assoc., II: 2-1-4 [4 a 6]-4-6-11+ 1 assoc., III: 1-1-2-2-4 ou 5-10(1), IV: 1-1-1-2-5 [ou 6] -10(1).

Macho. Medidas $(\mathrm{n}=50)$ - Comprimento do corpo (incluindo o rostro): 293(272-313) mm; Largura: 193 (177-209) $\mu \mathrm{m}$. Setas dorsais: $v 230$ (27-35), sc1 20 (14-27), sc2 31 (24-38), c112 (11-14), sc2 15 (11-22), c3 31 (24-38), d112 (8-16), d2 24 (16-30), e1 13 (11-19), e2 25 (22-33), f1 29 (24-33), f2 21 (1924), h1 23 (19-27). Coloração semelhante à da fêmea. Corpo delgado, alongado e afunilado na porção terminal. Apresentam as setas dorsais mais delgadas com as extremidades geralmente mais afiladas. Edéago com eixo do corpo reto, colo dirigido dorsalmente com curvatura em direção proximal e extremidade distal levemente aguda, formando um ângulo de cerca de $45^{\circ}$ em relação ao eixo do corpo. Quetotaxia (da coxa ao tarso) - I: 2-1-9-4-9(4)-14(2) + 1 assoc., II: 2-1-7-4-6(2)-12(1) + 1 assoc., III: 1-1-4-2-5-10(1), IV: 1-1-1-2-5 [ou 6] -10(1).

Observação. Eutetranychus banksi difere de E. orientalis Klein, 1936, por esta última apresentar as bases dos elementos dos pares $e 1$ e $f 1$ formando a figura de um quadrado, com área muito inferior à figura de trapézio presente em E. banksi. Além disso, difere na quetotaxia dos artículos das pernas e por $E$. orientalis apresentar a inserção da maioria das setas dorsais sobre tubérculos (Аттіан 1967).

\section{Morfometria}

A análise de box plot medianas e quartis do comprimento das setas dorsais indicou que as fêmeas oriundas de Citrus sp. puderam ser diferenciadas daquelas dos outros dois hospedeiros através do comprimento das setas $v 2, s c 2, c 1, c 2, c 3$ e $e 1$, sendo $v 2, s c 2, c 3$ menores e $c 1, c 2$ e $e 1$ maiores em comparação às de $H$. brasiliensis e $P$. aquatica, que não diferiram entre si (Figs 1-6). O tamanho do corpo (comprimento e largura do idiossoma) variou significativamente apenas nas fêmeas coletadas sobre H. brasiliensis de São José do Rio Preto sendo menores para as duas dimensões em relação a todas as outras populações (Figs 7 e 8). 

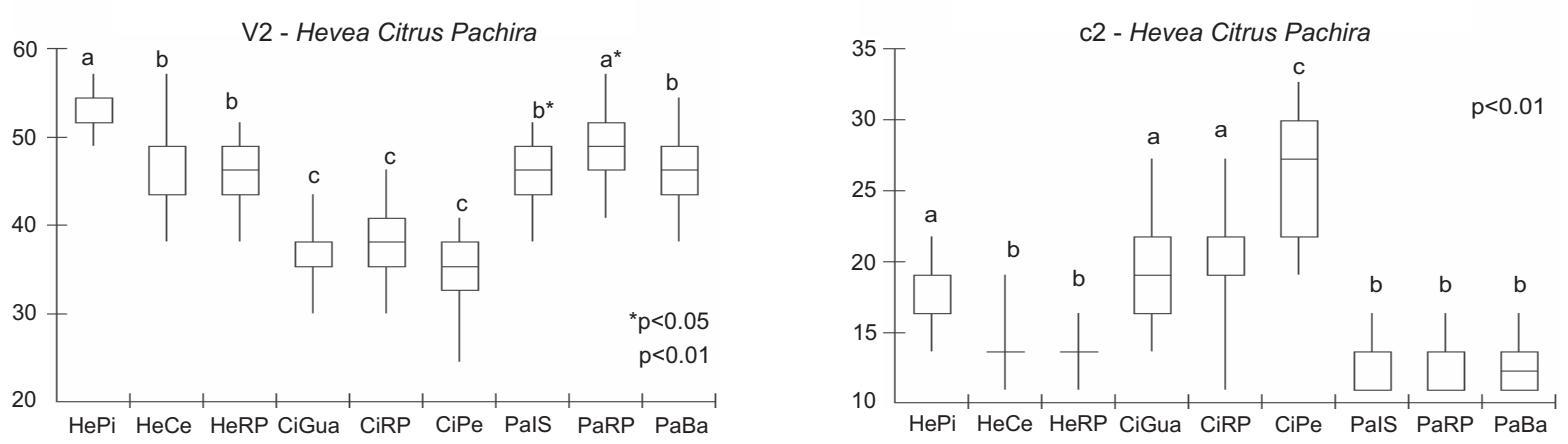

1
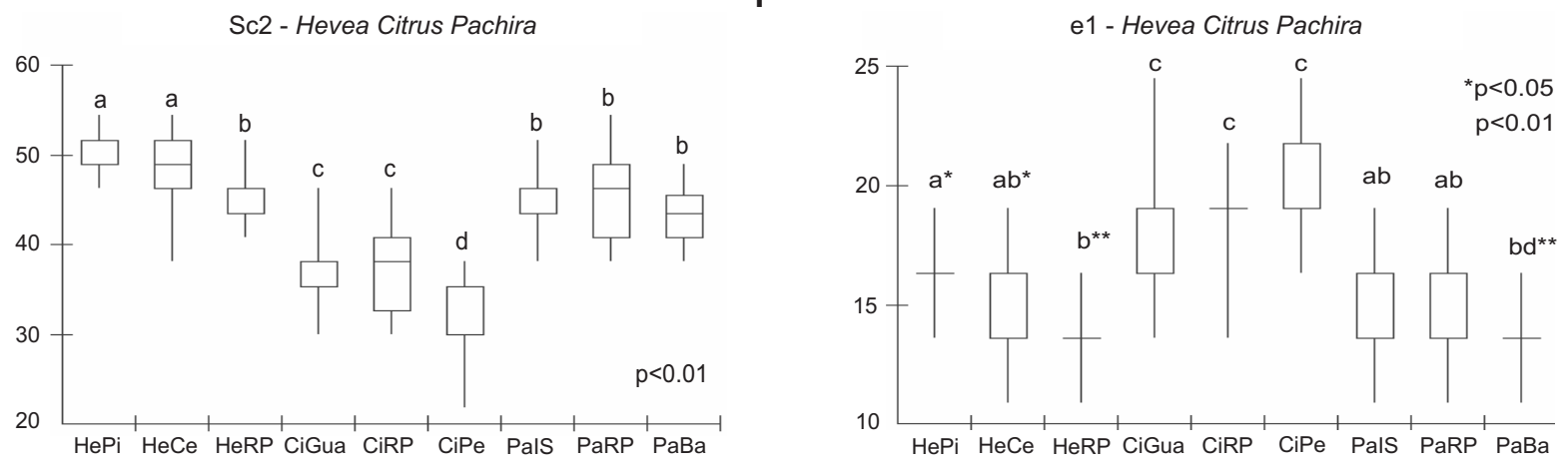

3
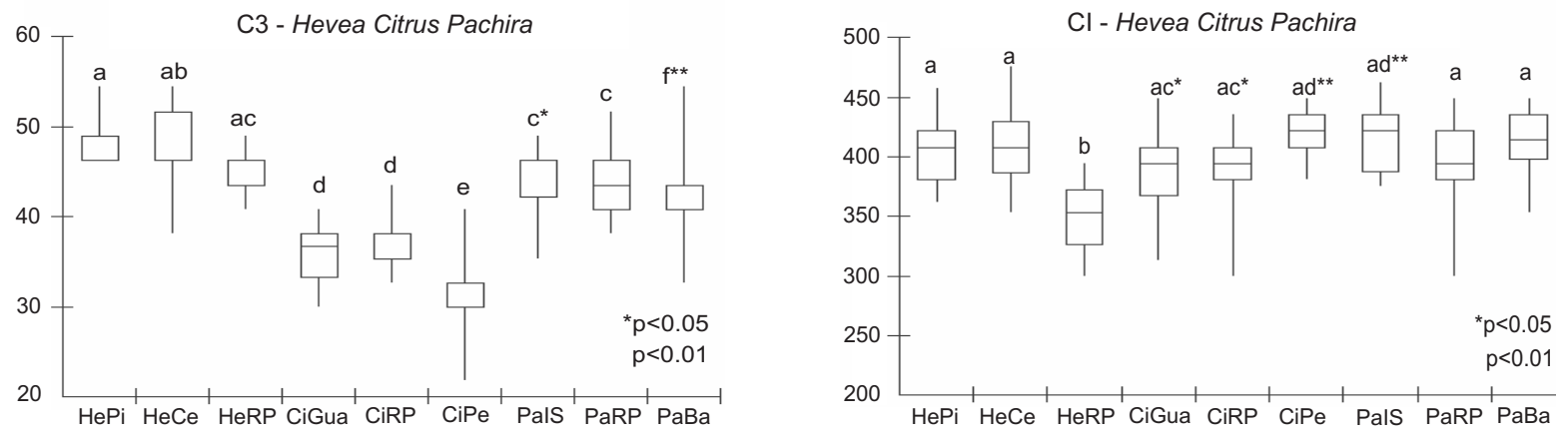

5
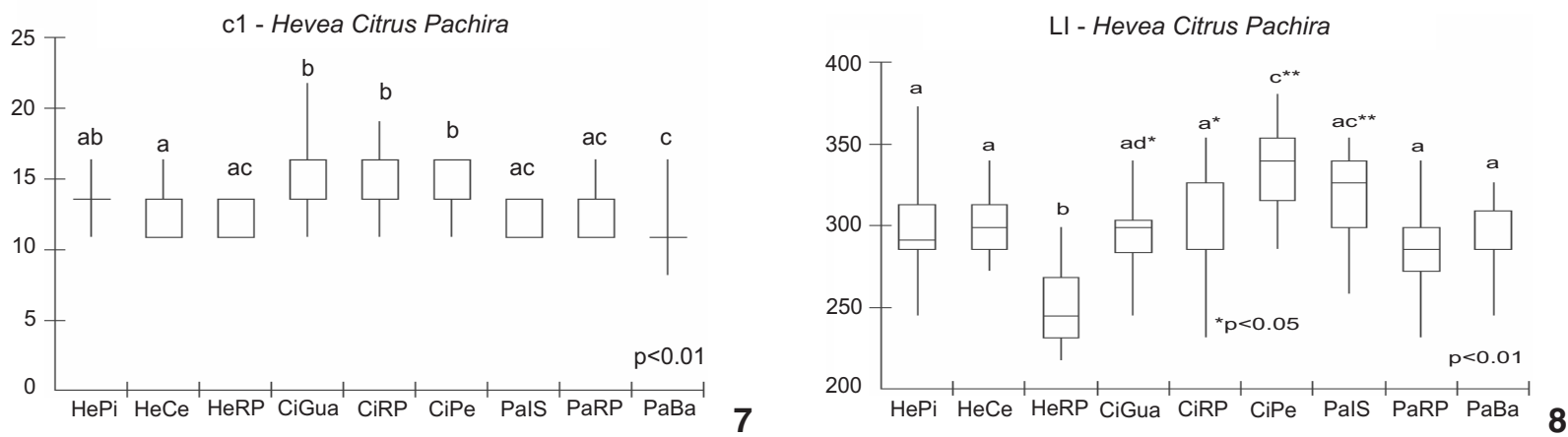

Figuras 1-8. Distribuição do comprimento das setas $(\mu \mathrm{m}) v 2, s c 2, c 3, c 1, c 2, e 1$ (1-6), comprimento do idiossoma (7) e largura do idiossoma (8) de fêmeas de E. banksi oriundas de H. brasiliensis, Citrus sp., e P. aquatica nas localidades de Piracicaba, Cedral e São José do Rio Preto: HePi, HeCe e HeRP; sobre Citrus sp., nas localidades de Guapiara, São José do Rio Preto e Recife: CiGua, CiRP e CiPe; e sobre P. aquatica nas localidades de llha Solteira, São José do Rio Preto e Bálsamo: PalS, PaRP e PaBa, respectivamente. 
A análise das distâncias entre elementos dos pares de setas dorsais resultou na correlação positiva entre a morfologia e o hospedeiro utilizado. Fêmeas de $H$. brasiliensis apresentaram as distâncias entre as setas $s c 2$ e $c 3, c 3$ e $c 2$ e $e 2$ e $e 1$, significativamente menores do que aquelas registradas nas fêmeas dos outros dois hospedeiros (Figs 9-11). Fêmeas oriundas $H$. brasiliensis de São José do Rio Preto apresentaram as distâncias entre as setas $s c 2$ e $c 3, c 2$ e $c 1, c 1$ e $d 1, d 2$ e $d 1$ e $d 1$ e $e 1$ menores em relação a todas as outras populações (Figs 9 e 13-16). Exceto pelas distâncias entre os elementos do par $d 1$ (d1-d1) não houve diferença nas distâncias entre os elementos dos pares de setas das fêmeas oriundas de Citrus sp. e P. aquatica (Figs 9-16).

Os testes multivariados aplicados à análise das variáveis canônicas para todas as combinações de populações foram significativos: Wilks' Lambda ( $\mathrm{p}<0,0001)$, Pillai's Trace $(\mathrm{p}<0,0001)$, Hotelling-Lawley Trace $(\mathrm{p}<0,0001)$ e Roy's Greatest Root $(\mathrm{p}<0,0001)$. A variação total explicada pela análise das populações, expressa em porcentagem, foi diretamente proporcional ao número e distância das localidades amostradas (Tab. II).
Houve diferença significativa na morfologia das fêmeas das diferentes populações estudadas quando comparados os diferentes hospedeiros, tendo sido individualizados três agrupamentos referentes aos mesmos (Figs 17 e 18). Houve maior diferenciação morfológica das fêmeas de Citrus sp., evidenciada pela distribuição das fêmeas deste hospedeiro nos valores negativos ao longo do eixo relativo à canônica 1 . As fêmeas oriundas dos hospedeiros $H$. brasiliensis e $P$. aquatica distribuíram-se ao longo dos valores positivos do eixo da canônica 1 e foram mais semelhantes entre si quando comparadas às de Citrus sp. (Figs 17-19). Para os caracteres tamanho do corpo e comprimento das setas dorsais $H$. brasiliensis e $P$. aquatica diferiram apenas pela distribuição ao longo do eixo relativo à canônica 2, contudo apresentaram sobreposição nos extremos dessa distribuição (Fig. 17). A sobreposição deixa de existir quando utilizados caracteres mais informativos sobre as diferenças entre essas populações (distâncias entre os elementos dos pares das setas dorsais) (Figs 18 e 19). A distribuição da análise com 29 caracteres distingue as populações por hospedeiro e localidade (Fig. 18) sendo que os caracteres de distância entre elemen-

Tabela II. Resultados da análise das Variáveis Canônicas de 15 caracteres morfológicos (tamanho do corpo e de setas dorsais do idiossoma), em fêmeas de populações de $E$. banksi. Proporção da variação total explicada conjunta e isoladamente pelas duas principais variáveis canônicas sobre a variação total das populações analisadas (\%) para todas as combinações de populações; caracteres morfológicos que influenciaram as variáveis canônicas e seus respectivos pesos em ordem decrescente de valor absoluto.

\begin{tabular}{|c|c|c|c|c|c|c|c|c|c|}
\hline \multicolumn{2}{|c|}{ Hevea, Citrus, Pachira $(8,2)$} & \multicolumn{2}{|c|}{ Hevea $(5,1)$} & \multicolumn{2}{|c|}{ Citrus $(7,4)$} & \multicolumn{2}{|c|}{ Pachira $(4,6)$} & \multicolumn{2}{|c|}{ Outros $(18,6)$} \\
\hline Can1 & Can2 & Can1 & Can2 & Can1 & Can2 & Can1 & Can2 & Can1 & Can2 \\
\hline$(42,4)$ & $(19,4)$ & $(49,3)$ & $(14,3)$ & $(41,3)$ & $(19,4)$ & $(41,2)$ & $(12,0)$ & $(64,2)$ & $(17,6)$ \\
\hline v2 & $\mathrm{d} 2$ & $\mathrm{LI}$ & $c 2$ & c3 & c2 & $\mathrm{Cl}$ & $\mathrm{LI}$ & c2 & $\mathrm{Cl}$ \\
\hline 0,9039 & 0,5665 & 0,8559 & 0,6750 & 0,8305 & 0,3621 & 0,5504 & 0,5811 & 0,9264 & 0,5656 \\
\hline sc2 & e2 & $\mathrm{Cl}$ & v2 & sc2 & $\mathrm{Cl}$ & sc1 & $\mathrm{f} 2$ & e1 & $\mathrm{LI}$ \\
\hline 0,9026 & 0,3832 & 0,8012 & 0,4837 & 0,8275 & 0,3366 & 0,5124 & 0,5422 & 0,7737 & 0,4917 \\
\hline c3 & f1 & $\mathrm{f} 2$ & sc1 & v2 & f1 & $\mathrm{LI}$ & d1 & d1 & sc1 \\
\hline 0,9013 & 0,2643 & 0,6258 & 0,2946 & 0,8235 & 0,3286 & 0,4506 & 0,3811 & 0,5840 & 0,3625 \\
\hline f1 & c3 & $\mathrm{sc} 2$ & $\mathrm{~d} 2$ & f1 & h1 & $\mathrm{f} 2$ & h1 & $\mathrm{LI}$ & $\mathrm{d} 2$ \\
\hline 0,8849 & 0,1522 & 0,4189 & 0,2315 & 0,7551 & 0,2493 & 0,4096 & 0,2691 & 0,5295 & 0,2154 \\
\hline h1 & c2 & h1 & e1 & h1 & sc1 & e1 & $c 3$ & sc1 & c1 \\
\hline 0,7448 & 0,0489 & 0,3734 & 0,0934 & 0,6713 & 0,1990 & 0,1979 & 0,2579 & 0,4784 & 0,1348 \\
\hline e2 & d1 & d1 & d1 & $\mathrm{f} 2$ & $\mathrm{LI}$ & c2 & e1 & c1 & $\mathrm{e} 2$ \\
\hline 0,6937 & 0,0478 & 0,2057 & 0,0927 & 0,6156 & 0,1435 & 0,1969 & 0,2089 & 0,4017 & 0,0512 \\
\hline $\mathrm{d} 2$ & c1 & c3 & $\mathrm{sc} 2$ & e2 & $\mathrm{f} 2$ & c1 & $\mathrm{Cl}$ & $\mathrm{Cl}$ & v2 \\
\hline 0,5232 & 0,0074 & 0,1200 & 0,0242 & 0,2868 & 0,1208 & 0,1932 & 0,1752 & 0,2069 & $-0,0184$ \\
\hline $\mathrm{f} 2$ & e1 & e1 & e2 & $\mathrm{d} 2$ & v2 & $\mathrm{sc} 2$ & f1 & $\mathrm{f} 2$ & c2 \\
\hline 0,4118 & $-0,0205$ & $-0,0072$ & $-0,0813$ & 0,2031 & 0,1034 & 0,1674 & 0,1641 & $-0,0952$ & $-0,0704$ \\
\hline $\mathrm{Cl}$ & $\mathrm{sc} 2$ & v2 & $\mathrm{LI}$ & c1 & $\mathrm{d} 2$ & d1 & c1 & h1 & f1 \\
\hline 0,2552 & $-0,0248$ & $-0,0254$ & $-0,1460$ & $-0,0680$ & $-0,0366$ & 0,1506 & 0,1025 & $-0,4175$ & $-0,0799$ \\
\hline sc1 & h1 & $c 2$ & $\mathrm{Cl}$ & $\mathrm{LI}$ & sc2 & h1 & sc2 & $\mathrm{d} 2$ & c3 \\
\hline 0,1910 & $-0,0744$ & $-0,0959$ & $-0,1471$ & $-0,1208$ & $-0,1410$ & $-0,024$ & 0,0198 & $-0,4855$ & $-0,1223$ \\
\hline
\end{tabular}



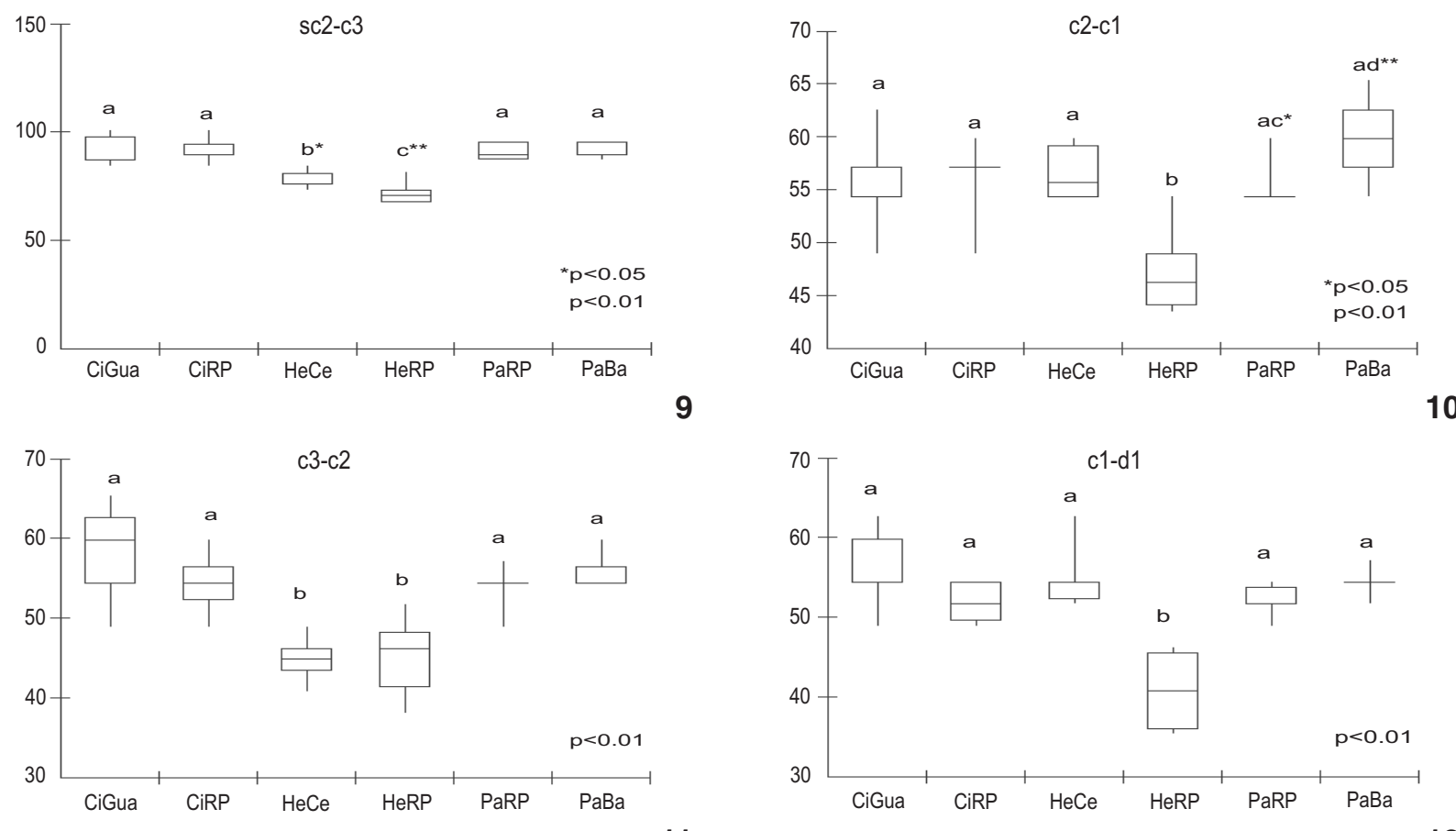

11
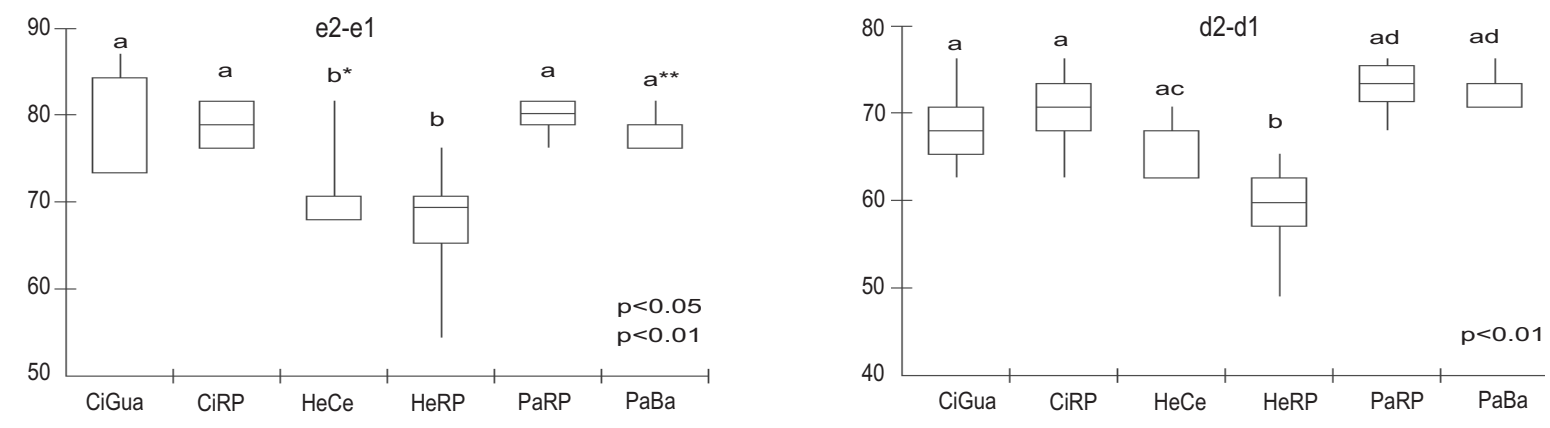

13
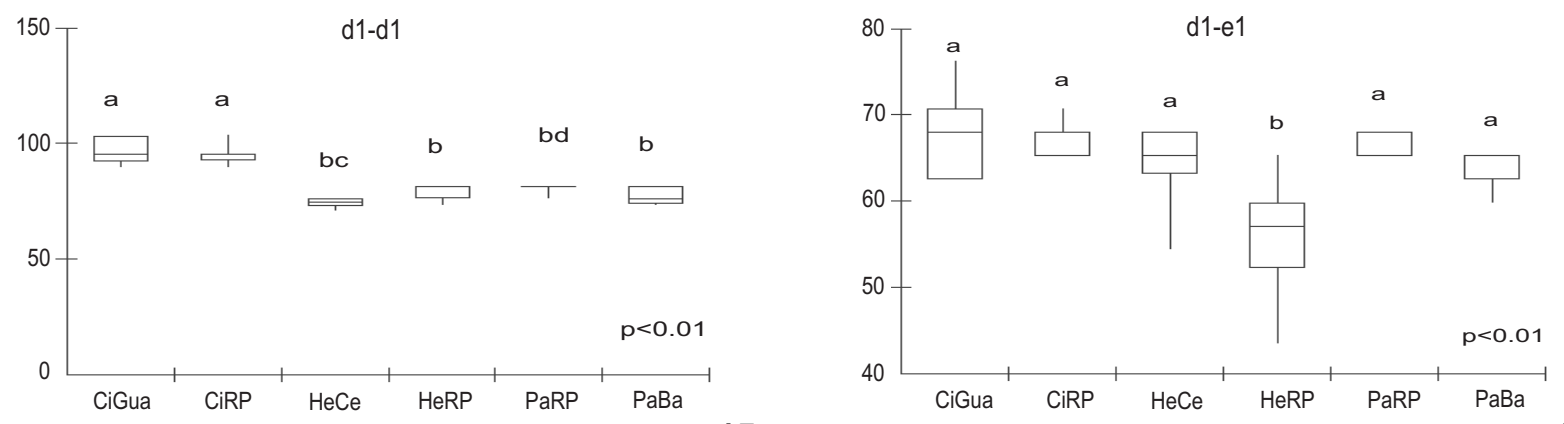

15

Figuras 9-16. Distribuição das distâncias entre os elementos dos pares de setas ( $\mu \mathrm{m})$ sc2 e $c 3, c 3$ e $c 2, e 2$ e e1, d1 e d1, c2 e $c 1, c 1$ e d1, $d 2$ e d1, $d 1$ e e 1 de fêmeas de E. banksi oriundas de Citrus sp., H. brasiliensis e $P$. aquatica nas localidades de Piracicaba, Cedral e São José do Rio Preto: HePi, HeCe e HeRP; sobre Citrus sp. nas localidades de Guapiara, São José do Rio Preto e Recife: CiGua, CiRP e CiPe; e sobre P. aquatica nas localidades de Ilha Solteira, São José do Rio Preto e Bálsamo: PalS, PaRP e PaBa, respectivamente. 

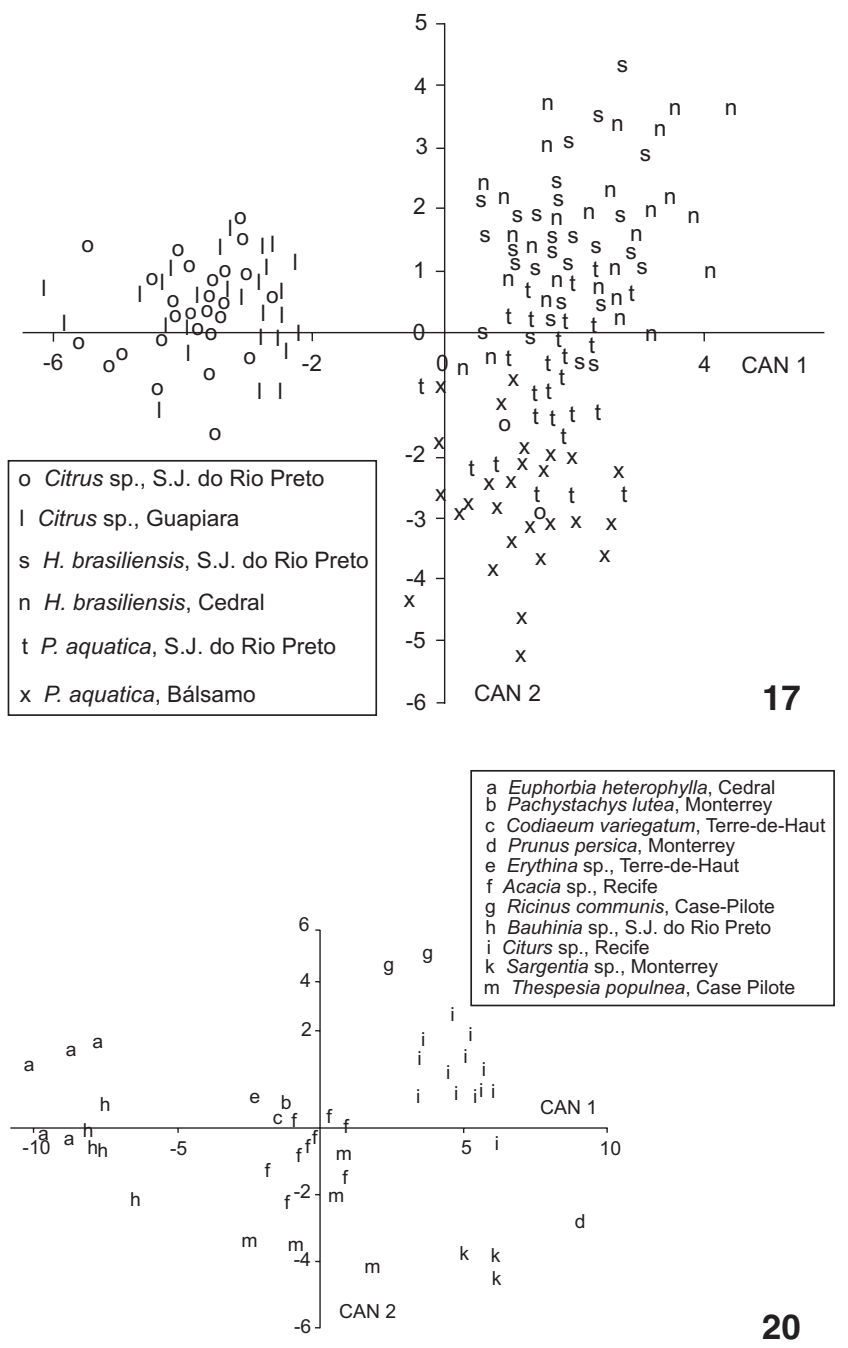
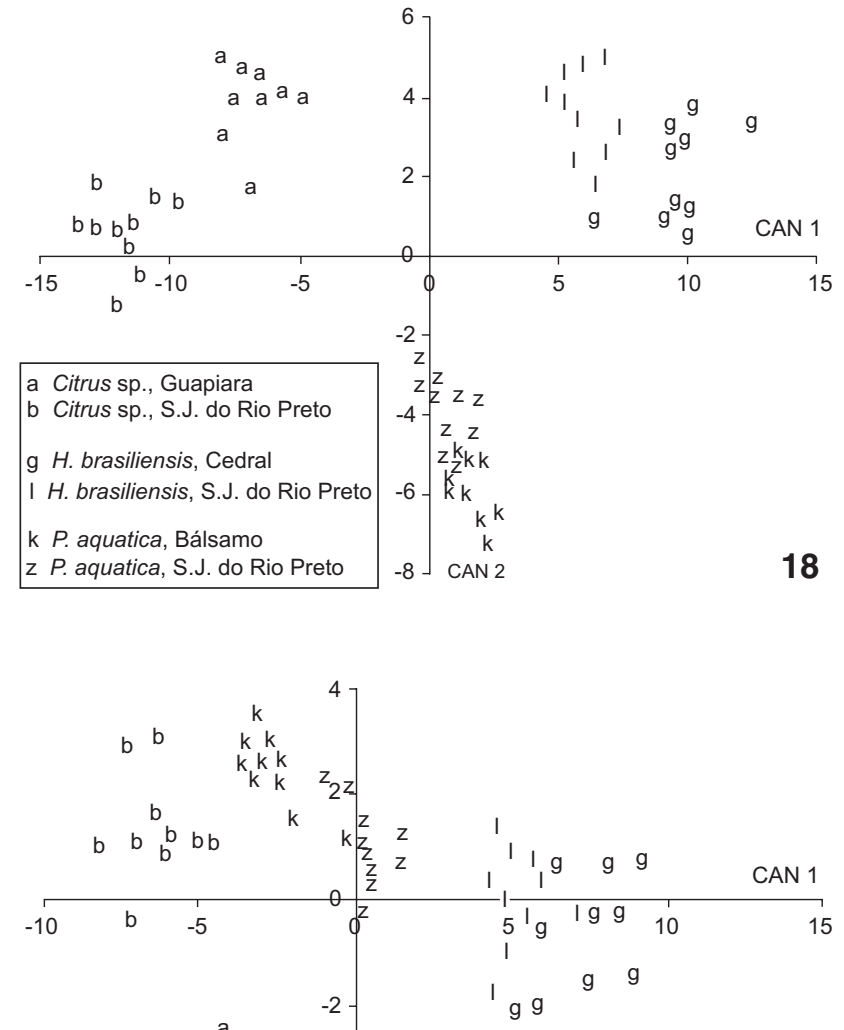

a Citrus sp., Guapiara

b Citrus sp., S.J. do Rio Preto

g $H$. brasiliensis, Cedral

I H. brasiliensis, S.J. do Rio Preto

k P. aquatica, Bálsamo

z P. aquatica, S.J. do Rio Preto

19

Figuras 17-20. Distribuição morfométrica de fêmeas de E. banksi utilizando-se três combinações de caracteres morfológicos: 1) comprimento e largura do idiossoma e tamanho das setas dorsais. 2) comprimento e largura do idiossoma, tamanho das setas dorsais e distâncias entre os elementos de quatorze pares de setas dorsais. 3) distâncias entre os elementos de quatorze pares de setas dorsais. Localidades das coletas das fêmeas nas legendas das figuras. (17) combinação 1 para 180 fêmeas oriundas dos hospedeiros $H$. brasiliensis, Citrus sp. e P. aquatica de duas localidades cada hospedeiro; (18) combinação 2 para 60 fêmeas oriundas dos mesmos hospedeiros da figura anterior; (19) combinação 3 para as mesmas fêmeas da figura anterior; (20) combinação 1 para 52 fêmeas de hospedeiros no Brasil, Guadalupe, Martinica, México e Paraguai.

tos de setas são os mais importantes para distinguir localidades, ainda que respondam por apenas 2,9\% da variação total (Fig. 19). A variação total da distribuição morfométrica das seis populações de três hospedeiros $(n=180)$ e localidades próximas (estado de São Paulo) foi de 8,2\% (Fig. 17) enquanto que na análise de fêmeas de onze hospedeiros e quatro países $(n=52)$ a variação total foi de $18,6 \%$ (Fig. 20). Isso indica distância morfológica acumulada entre diferentes localidades e hospedeiros que pode ser observada pela ampla dispersão das populações ao longo dos eixos das canônicas 1 e 2. Na distribuição morfométrica de fêmeas de $E$. banksi coletadas em $H$. brasiliensis de cinco localidades foi de $5,1 \%$ (Fig. 21); e em $P$. aquatica de três localidades de $4,6 \%$ (Fig. 22) sendo as duas últimas análises relativas a populações próximas. Já para fêmeas oriundas de Citrus sp. do Brasil, de Guadalupe e do Paraguai a variação total foi de 7,4\% (Fig. 23).

Quando representada a distribuição das setas dorsais do idiossoma de três fêmeas representativas dos três hospedeiros, constatamos que a diferença entre elas pode ser de difícil percepção e os padrões existentes são evidenciados somente atra- 
Tabela III. Resultados da análise das Variáveis Canônicas de 29 caracteres (tamanho de corpo e de setas dorsais do idiossoma; distância entre as setas) de fêmeas de mesmas populações de $E$. banksi. Proporção da variação total explicada conjunta e isoladamente pelas duas principais variáveis canônicas sobre a variação total das populações analisadas (\%) para combinações de três populações; caracteres morfológicos que influenciaram as cinco primeiras variáveis canônicas e seus respectivos pesos, em ordem decrescente de valor absoluto.

\begin{tabular}{|c|c|c|c|c|c|}
\hline \multicolumn{2}{|c|}{ Tamanho das setas } & \multicolumn{2}{|c|}{ Todos os caracteres } & \multicolumn{2}{|c|}{ Distância entre setas } \\
\hline \multicolumn{2}{|c|}{ Hevea, Citrus, Pachira $(8,2)$} & \multicolumn{2}{|c|}{ Hevea, Citrus, Pachira $(12,2)$} & \multicolumn{2}{|c|}{ Hevea, Citrus, Pachira $(2,9)$} \\
\hline Can1 & Can2 & Can1 & Can2 & Can1 & Can2 \\
\hline$-42,4$ & $-19,4$ & $-39,6$ & $-16,2$ & $-49,5$ & -20 \\
\hline v2 & $\mathrm{d} 2$ & c3 & $d 2$ & $\mathrm{c} 1-\mathrm{c} 1$ & $c 1-d 1$ \\
\hline 0,904 & 0,57 & 0,77 & 0,72 & 0,939 & 0,74 \\
\hline sc2 & e2 & f1 & e2 & d1-d1 & e1-e1 \\
\hline 0,903 & 0,38 & 0,76 & 0,626 & 0,886 & 0,679 \\
\hline c3 & $\mathrm{f1}$ & $\mathrm{LI}$ & e1 & e1-e1 & sc2-c3 \\
\hline 0,901 & 0,26 & 0,74 & 0,489 & 0,496 & 0,595 \\
\hline f1 & c3 & sc2 & c2 & $s c 2-c 3$ & $c 2-c 1$ \\
\hline 0,885 & 0,15 & 0,71 & 0,434 & 0,454 & 0,546 \\
\hline h1 & c2 & v2 & c1 & $c 3-c 2$ & $\mathrm{~d} 2-\mathrm{d} 1$ \\
\hline 0,745 & 0,05 & 0,71 & 0,377 & 0,316 & 0,407 \\
\hline
\end{tabular}

vés da análise morfométrica (Fig. 24 e Tab. II - valores morfométricos citados).

A variação total explicada pela análise conjunta do comprimento e largura do corpo, comprimento e distância de inserção entre pares de setas dorsais foi de $12,2 \%$. Isoladamente, a variação total encontrada foi de $8,2 \%$ para o comprimento e largura do corpo e comprimento das setas (15 caracteres) e de apenas $2,9 \%$ para distâncias entre setas (14 caracteres). O caráter que mais influenciou a canônica 1 diferiu nas análises sendo $v 2$ para a análise isolada e $c 3$ para a conjunta (Tab. III).

As fêmeas dos três hospedeiros das seis localidades apresentaram variação no número de setas táteis dos fêmures I e II e das tíbias III e IV. A variação encontrada no número das setas está presente nas seis populações estudadas e não foi relacionada com o hospedeiro utilizado (Tab. IV). As setas quimiossensoriais não variaram em número. A disposição das setas também não variou nos artículos das pernas.

\section{Biologia}

A duração da maioria das fases da vida (ovo, larva, protocrisálida, protoninfa, deutocrisálida e deutoninfa) (Tab. V) e do período de pré-oviposição e a longevidade (Tab. VI) de fêmeas de $E$. banksi provenientes de $P$. aquatica foi significativamente maior quando comparada com a daquelas provenientes dos outros dois hospedeiros, que não apresentaram diferença significativa entre si para a duração das fases de vida e período de préoviposição. A fecundidade das fêmeas oriundas de P. aquatica foi a menor encontrada entre as populações estudadas e diferiu sig-
Tabela IV. Variação na quetotaxia das pernas I a IV das fêmeas de E. banksi oriundas de $H$. brasiliensis, Citrus sp. e $P$. aquatica dos municípios de São José do Rio Preto, Cedral, Guapiara e Bálsamo.

\begin{tabular}{|c|c|c|c|c|}
\hline \multirow{2}{*}{$\frac{\text { H. brasiliensis }}{\text { Perna }}$} & \multicolumn{2}{|c|}{ Cedral } & \multicolumn{2}{|c|}{ São José do Rio Preto } \\
\hline & Fêmur & Tíbia & Fêmur & Tíbia \\
\hline I & 6 & $9(1)$ & 6 a 7 & $9(1)$ \\
\hline II & 4 a 6 & 6 & 4 a 6 & 6 \\
\hline III & 2 & 4 a 5 & 2 & 5 \\
\hline IV & 1 & 5 a 6 & 1 & 5 a 6 \\
\hline
\end{tabular}

\begin{tabular}{ccccccc}
\hline Citrus sp. & & \multicolumn{2}{c}{ Guapiara } & & \multicolumn{2}{c}{ São José do Rio Preto } \\
\cline { 1 - 1 } \cline { 6 - 7 } \cline { 5 - 6 } Perna & & Fêmur & Tíbia & & Fêmur & Tíbia \\
\hline I & 6 a 7 & $9(1)$ & & 6 & 9 (1) \\
II & 4 a 5 & 6 & & 4 a 5 & 6 \\
III & 2 & 5 & & 2 & 4 a 5 \\
IV & 1 & 5 a 6 & & 1 & 5 a 6 \\
\hline
\end{tabular}

\begin{tabular}{ccccccc}
\hline \multirow{2}{*}{ P. aquatica } & & \multicolumn{2}{c}{ Bálsamo } & & \multicolumn{2}{c}{ São José do Rio Preto } \\
\cline { 1 - 1 } \cline { 6 - 7 } \cline { 5 - 6 } Perna & & Fêmur & Tíbia & & Fêmur & Tíbia \\
\hline I & 6 a 7 & $9(1)$ & & 6 a 7 & 9 (1) \\
II & 4 a 6 & 6 & & 4 a 5 & 6 \\
III & 2 & 4 a 5 & & 2 & 4 a 5 \\
\hline
\end{tabular}


Tabela V. Duração (dias) e sobrevivência (\%) dos estágios de ovo, larva, protocrisálida, protoninfa, deutocrisálida, deutoninfa, telocrisálida e período de ovo a adulto de indivíduos de $E$. banksi coletados e criados sobre seus hospedeiros de origem. $\mathrm{BOD}$ a $28 \pm 1{ }^{\circ} \mathrm{C}$ e 12 horas de fotofase; $70 \pm 10 \%$ UR. Médias \pm EP seguidas pela mesma letra na coluna não diferem estatisticamente entre si pelo teste de Tukey $(p<0,01)$ e com "*" diferem estatisticamente entre si pelo teste de Tukey $(p<0,05)$.

\begin{tabular}{|c|c|c|c|c|}
\hline \multirow{2}{*}{ Estágio } & \multirow{2}{*}{ Parâmetro } & \multicolumn{3}{|c|}{ Hospedeiros } \\
\hline & & H. brasiliensis $(n=19)$ & C. sinensis $(n=18)$ & P. aquatica $(n=14)$ \\
\hline \multirow[t]{2}{*}{ Ovo } & Duração & $5.2 \pm 0.03 a$ & $5.3 \pm 0,11 a^{*}$ & $5,7 \pm 0,14 b^{*}$ \\
\hline & Sobrevivência & 100 & 100 & 100 \\
\hline \multirow[t]{2}{*}{ Larva } & Duração & $1,7 \pm 0,13 a^{*}$ & $1,3 \pm 0,09 a$ & $3,1 \pm 0,49 b^{*}$ \\
\hline & Sobrevivência & 100 & 100 & 100 \\
\hline \multirow[t]{2}{*}{ Protocrisálida } & Duração & $0,6 \pm 0,03 a$ & $0,5 \pm 0,05 a$ & $0,9 \pm 0,08 b$ \\
\hline & Sobrevivência & $89,5 \pm 0,07$ & 100 & 100 \\
\hline \multirow[t]{2}{*}{ Protoninfa } & Duração & $0,7 \pm 0,13 a$ & $0,7 \pm 0,06 a$ & $2,4 \pm 0,59 b$ \\
\hline & Sobrevivência & $89,5 \pm 0,07$ & 100 & $64,3 \pm 0,13$ \\
\hline \multirow[t]{2}{*}{ Deutocrisálida } & Duração & $0,7 \pm 0,07 a$ & $0,5 \pm 0,04 a$ & $0,9 \pm 0,14 b$ \\
\hline & Sobrevivência & $89,5 \pm 0,07$ & 100 & $64,3 \pm 0,13$ \\
\hline \multirow[t]{2}{*}{ Deutoninfa } & Duração & $0,9 \pm 0,11 a$ & $0,8 \pm 0,06 a$ & $1,6 \pm 0,22 b$ \\
\hline & Sobrevivência & $79,8 \pm 0,10$ & 100 & $50 \pm 0,14$ \\
\hline \multirow[t]{2}{*}{ Telocrisálida } & Duração & $0,8 \pm 0,06 a$ & $0,8 \pm 0,05 a$ & $1,0 \pm 1,65 a$ \\
\hline & Sobrevivência & $73,7 \pm 0,10$ & 100 & $50 \pm 0,14$ \\
\hline \multirow[t]{2}{*}{ Ovo-adulto } & Duração & $14,8 \pm 1,25 a$ & $19,9 \pm 1,19 a$ & $17,6 \pm 2,04 a$ \\
\hline & Sobrevivência & $68,4 \pm 0,11$ & 100 & $50 \pm 0,14$ \\
\hline
\end{tabular}

Tabela VI. Duração (dias) dos períodos de pré-oviposição, oviposição e longevidade das fêmeas de $E$. banksi sobre três hospedeiros. Fecundidade expressa em número de ovos por fêmea. BOD a $28 \pm 1{ }^{\circ} \mathrm{C}$ e 12 horas de fotofase; $70 \pm 10 \%$ UR. Médias \pm EP seguidas de mesma letra na coluna não diferem estatisticamente entre si pelo teste de Tukey $(p<0,01)$.

\begin{tabular}{ccccc}
\hline Hospedeiros/Parâmetro & Pré-oviposição & Oviposição & Fecundidade & Longevidade fêmea \\
\hline Hevea brasiliensis $(\mathrm{n}=45)$ & $1,05 \pm 0,12 \mathrm{a}$ & $9,85 \pm 0,25 \mathrm{a}$ & $48,0 \pm 1,99 \mathrm{a}$ & $20,46 \pm 0,25 \mathrm{a}$ \\
Citrus sinensis $(\mathrm{n}=42)$ & $0,91 \pm 0,13 \mathrm{a}$ & $7,61 \pm 0,26 \mathrm{~b}$ & $22,5 \pm 1,24 \mathrm{~b}$ & $17,52 \pm 0,26 \mathrm{~b}$ \\
Pachira aquática $(\mathrm{n}=45)$ & $1,57 \pm 0,09 \mathrm{~b}$ & $8,0 \pm 0,30 \mathrm{~b}$ & $15,6 \pm 0,97 \mathrm{c}$ & $23,60 \pm 0,30 \mathrm{c}$ \\
\hline
\end{tabular}

nificativamente entre os três hospedeiros estudados (Tab. VI) mantendo-se semelhante por três gerações consecutivas (Tab. VII).

A oviposição de fêmeas de $E$. banksi provenientes de $P$. aquatica ocorreu neste e nos outros dois hospedeiros testados e a média diária foi menor no hospedeiro original, sendo $C$. sinensis o melhor substrato para essa população, seguido por $H$. brasiliensis. Não ocorreu oviposição em hospedeiros trocados em três tratamentos, dois deles tendo P. aquatica como substrato. Fêmeas oriundas de C. sinensis não foram capazes de utilizar outras espécies vegetais como substrato. Apenas uma fêmea proveniente de $H$. brasiliensis efetuou postura em outra espécie vegetal, P. aquatica (Tab. VIII).
Tabela VII. Fecundidade (número de ovos/fêmea) e erro padrão da média nas gerações F1, F2 e F3 de $E$. banksi sobre $H$. brasiliensis, C. sinensis e $P$. aquatica. BOD a $28 \pm 1{ }^{\circ} \mathrm{C}$ e 12 horas de fotofase; $70 \pm 10 \%$ UR. Médias \pm EP seguidas pela mesma letra na linha e na coluna não diferem estatisticamente entre si pelo teste de Tukey $(p<0,01)$.

\begin{tabular}{cccc}
\hline \multirow{2}{*}{ Geração } & \multicolumn{3}{c}{ Hospedeiro } \\
\cline { 2 - 4 } & H. brasiliensis & C. sinensis & P. aquatica \\
\hline F1 & $55,2 \pm 2,3$ ad & $20,2 \pm 2,3$ b & $13,6 \pm 1,6 \mathrm{c}$ \\
F2 & $47,8 \pm 3,5$ a & $21,9 \pm 2,0 \mathrm{~b}$ & $17,6 \pm 1,8 \mathrm{c}$ \\
F3 & $41 \pm 3,6$ ae & $25,4 \pm 2,0 \mathrm{~b}$ & $15,6 \pm 1,5 \mathrm{c}$ \\
\hline
\end{tabular}



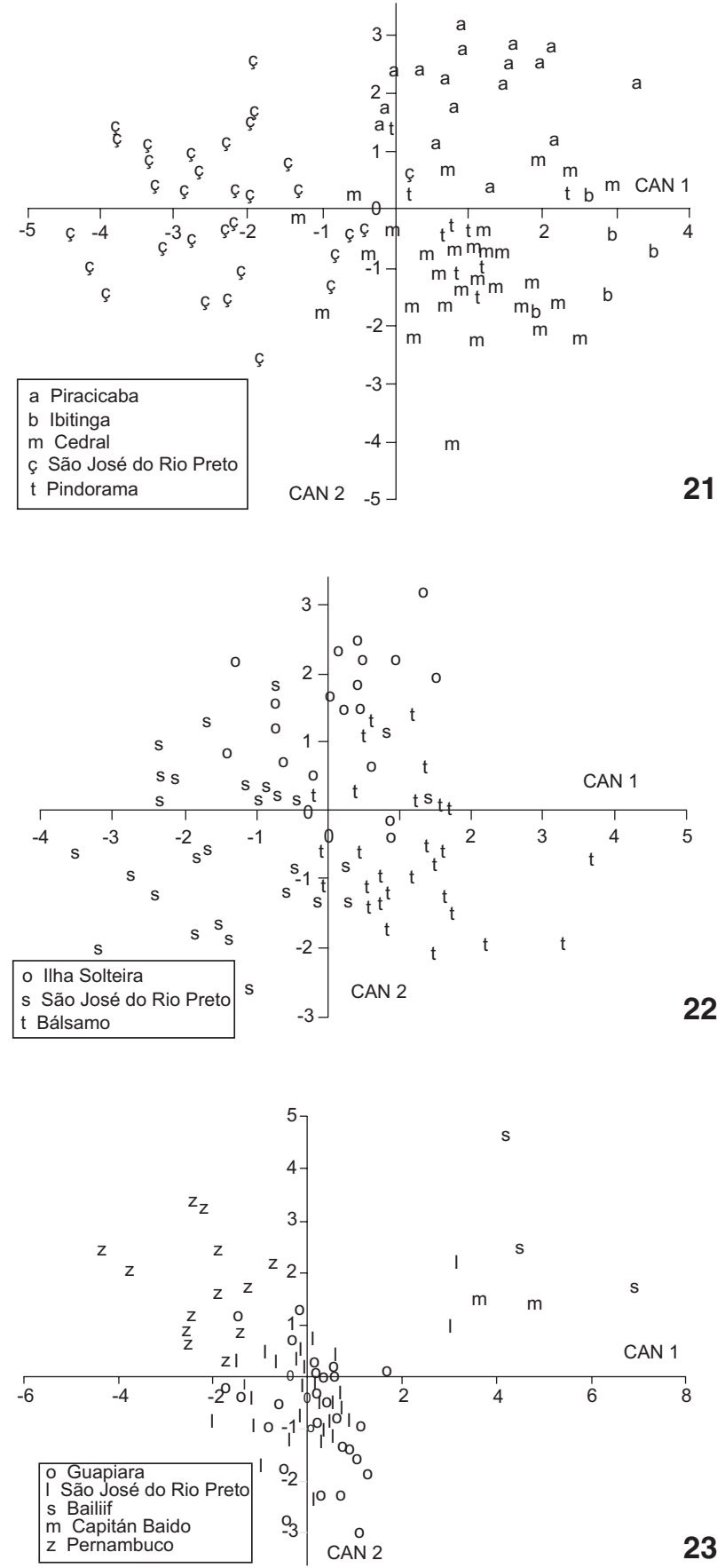

Figuras 21-23. Distribuição morfométrica com 15 caracteres, comprimento e largura do idiossoma e comprimento das setas dorsais, de fêmeas de E. banksi para todas as localidades de cada hospedeiro analisada isoladamente. Localidades das coletas nas legendas das figuras. (21) 91 fêmeas oriundas de $H$. brasiliensis de localidades próximas; (22) 79 fêmeas oriundas de $P$. aquatica também de localidades próximas; (23) 78 fêmeas oriundas de Citrus sp. no Brasil Guadalupe e Paraguai.
Tabela VIII. Ocorrência de oviposição, número de fêmeas que ovipositaram e respectivas médias e erro padrão do número de ovos/fêmea/dia de E. banksi criadas em folhas dos seus hospedeiros de origem e outros dois hospedeiros. $\mathrm{H}$. brasiliensis (HE), C. sinensis $(\mathrm{Cl})$ e $P$. aquatica (PA). BOD a $28 \pm 1^{\circ} \mathrm{C}$ e 12 horas de fotofase; $70 \pm 10 \%$ UR. Médias \pm EP seguidas pela mesma letra na coluna não diferem estatisticamente entre si pelo teste de Tukey $(p<0,01)$ e com $" * *$ diferem estatisticamente entre si pelo teste de Tukey $(p<0,05)$.

\begin{tabular}{ccrrl}
\hline $\begin{array}{c}\text { Origem } \\
\text { dos ácaros }\end{array}$ & $\begin{array}{c}\text { Hospedeiro } \\
\text { (substrato) }\end{array}$ & $\mathrm{n}$ & Média $\pm \mathrm{EP}$ & \\
\hline $\mathrm{HE}$ & $\mathrm{HE}$ & 15 & $3,5 \pm 0,4$ & $\mathrm{a}^{*}$ \\
$\mathrm{HE}$ & $\mathrm{Cl}$ & 1 & $1,5 \pm 0,9$ & $\mathrm{~b}^{\star *}$ \\
$\mathrm{HE}$ & $\mathrm{PA}$ & & & \\
$\mathrm{Cl}$ & $\mathrm{Cl}$ & 13 & $3,6 \pm 0,2$ & $\mathrm{a}^{*}$ \\
$\mathrm{Cl}$ & $\mathrm{HE}$ & & & \\
$\mathrm{Cl}$ & $\mathrm{PA}$ & & & \\
$\mathrm{PA}$ & $\mathrm{PA}$ & 15 & $1,4 \pm 0,1$ & $\mathrm{~b}$ \\
$\mathrm{PA}$ & $\mathrm{HE}$ & 8 & $1,6 \pm 0,3$ & $\mathrm{~b}$ \\
$\mathrm{PA}$ & $\mathrm{Cl}$ & 9 & $2,4 \pm 0,3$ & $\mathrm{ab}$ \\
\hline
\end{tabular}

O intercruzamento de indivíduos oriundos de $H$. brasiliensis com os de C. sinensis e $P$. aquatica produziu prole. Machos e fêmeas provenientes de $P$. aquatica não foram capazes de se reproduzir com aqueles de $C$. sinensis. A prole obtida nos demais intercruzamentos foi cruzada entre si até a terceira geração e produziu descendência fértil, exceto para o cruzamento de fêmeas de $H$. brasiliensis com machos de $C$. sinensis que não produziu prole a partir da segunda geração (Tab. IX). A impossibilidade desse cruzamento deveu-se à redução populacional causada pela baixa fecundidade (número de ovos/fêmea) F1 $(10,5)$ e F2 $(9,5)$ e grande inviabilidade na fase de ovo

Tabela IX. Intercruzamento de indivíduos de E. banksi oriundos dos hospedeiros $\mathrm{H}$. brasiliensis (HE), $C$. sinensis $(\mathrm{Cl})$ e $P$. aquatica $(\mathrm{PA})$. Utilizou-se como substrato folhas do hospedeiro da fêmea. Obtenção de prole em três gerações e respectiva razão sexual da prole. BOD a $28 \pm 1{ }^{\circ} \mathrm{C}$ e 12 horas de fotofase; $70 \pm 10 \%$ UR. Os valores não diferiram entre si através da análise de variância ANOVA.

\begin{tabular}{|c|c|c|c|c|c|c|c|}
\hline \multicolumn{2}{|c|}{$\begin{array}{c}\text { População de origem } \\
\text { do indivíduo }\end{array}$} & \multicolumn{3}{|c|}{ Obtenção de Prole } & \multicolumn{3}{|c|}{ Razão sexual } \\
\hline Fêmea & Macho & $\mathrm{F} 1$ & $\mathrm{~F} 2$ & F3 & $\mathrm{F} 1$ & F2 & $\mathrm{F} 3$ \\
\hline $\mathrm{HE}$ & $\mathrm{HE}$ & + & + & + & 1,34 & 1,44 & 1,36 \\
\hline $\mathrm{HE}$ & $\mathrm{Cl}$ & + & + & & 1,17 & 1,50 & \\
\hline $\mathrm{Cl}$ & $\mathrm{HE}$ & + & + & + & 1,42 & 1,34 & 1,44 \\
\hline $\mathrm{Cl}$ & $\mathrm{Cl}$ & + & + & + & 1,19 & 1,17 & 1,15 \\
\hline $\mathrm{HE}$ & PA & + & + & + & 1,38 & 1,33 & 1,44 \\
\hline PA & $\mathrm{HE}$ & + & + & + & 1,25 & 1,29 & 1,42 \\
\hline PA & PA & + & + & + & 1,25 & 1,14 & 1,24 \\
\hline $\mathrm{Cl}$ & PA & & & & & & \\
\hline PA & $\mathrm{Cl}$ & & & & & & \\
\hline
\end{tabular}




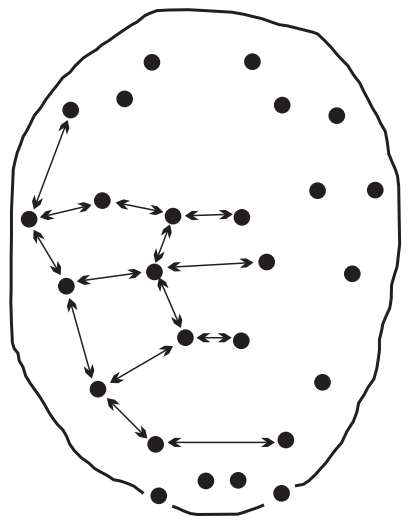

on Hevea brasiliensis
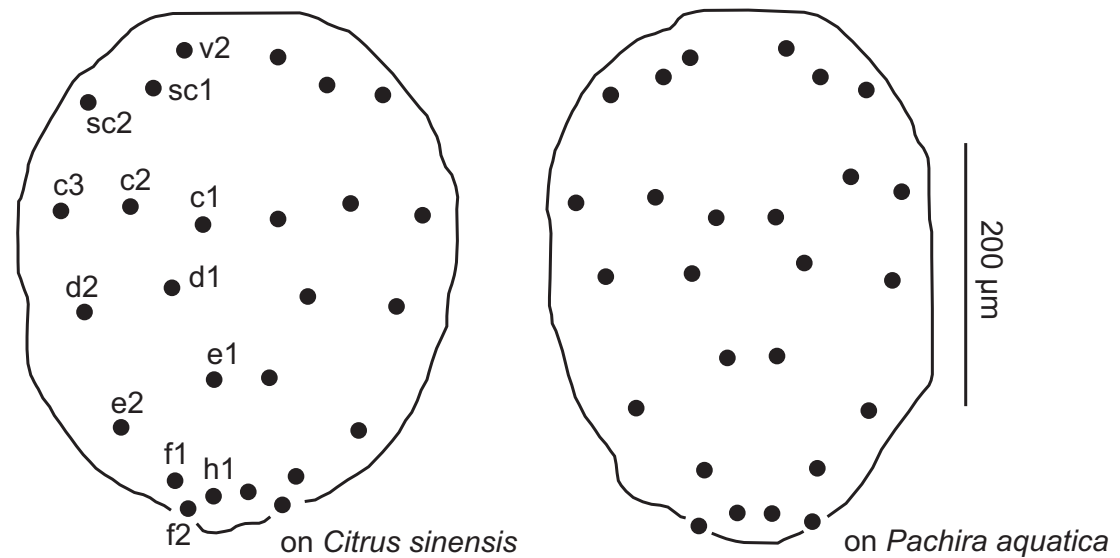

Figura 24. Padrão de distribuição das setas dorsais do idiossoma de fêmeas de E. banksi oriundas de $H$. brasiliensis, Citrus sp. e $P$. aquatica (DZSJRP, $\mathrm{n}^{\circ}$ 6767, 6632 e 6574, respectivamente). Distâncias entre elementos dos pares de setas: sc2-c3, c1-c1, c1-c2, c2-c3, c1-d1, d1d1, d1-d2, d1-e1, e1-e1, e1-e2, e2-f1,f1-f1.

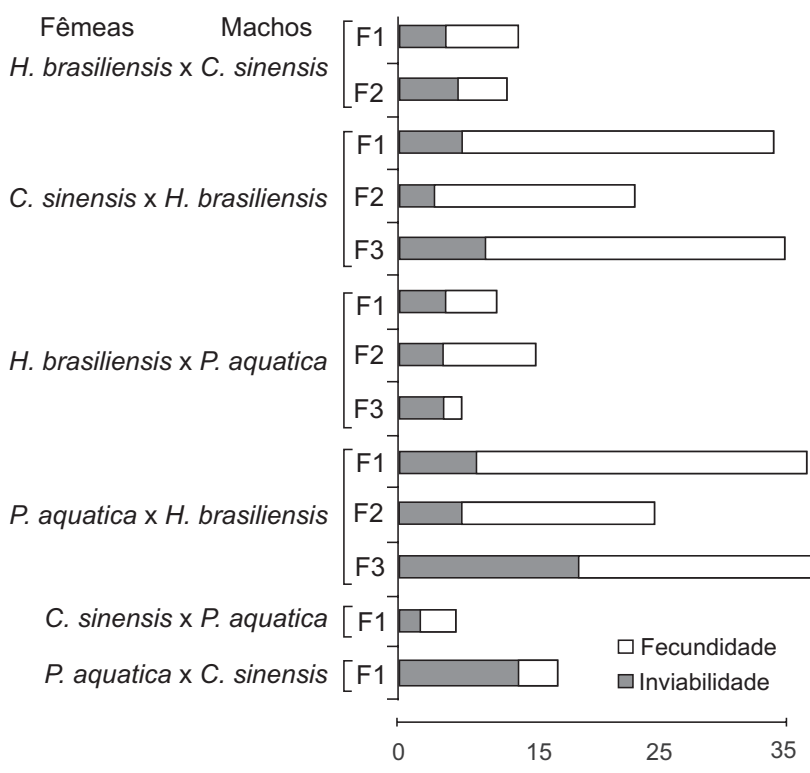

Figura 25. Fecundidade, expressa em número de ovos/fêmea, e inviabilidade na fase de ovo nos intercruzamento de indivíduos de E. banksi oriundos de três hospedeiros (usando-se como substrato folhas do hospedeiro da fêmea) por três gerações consecutivas (BOD a $28 \pm 1^{\circ} \mathrm{C}$ e 12 horas de fotofase; $70 \pm 10 \%$ UR).

observada nas duas gerações F1 (36,9\%) e F2 (52,1\%). Registrou-se inviabilidade na fase de ovo muito maior em todos os intercruzamentos $(13,7$ a $73,2 \%)$ (Fig. 25) do que nas populações-controle do mesmo experimento ( $8 \%$ sobre $H$. brasiliensis; $9,1 \%$ sobre $C$. sinensis e $7,2 \%$ sobre $P$. aquatica).

A razão sexual nos intercruzamentos não diferiu da observada nas populações originais por três gerações consecutivas e também não variou significativamente em relação ao substrato utilizado (Tab. IX). Eventos de partenogênese arrenótoca exclusiva (onde a fêmea produz somente descendentes machos) foram observados em $46,7 \%$ das tentativas de cruzamentos da geração F1 em que as fêmeas receberam machos oriundos de outro hospedeiro. Nas gerações consecutivas, a ocorrência de partenogênese arrenótoca exclusiva caiu para $21,6 \%$ na geração F2 e apenas 2,6\% na geração F3. Contudo, a ocorrência de prole também diminuiu ao longo das gerações, tendo ocorrido, respectivamente, 75,51 e 38 ocorrências de prole do total de 90, 54 e 49 tentativas respectivamente. Os cruzamentos sem produção de prole e a ocorrência de partenogênese arrenótoca exclusiva foram, respectivamente, 4 e 13 entre as populações de $H$. brasiliensis e $C$. sinensis; 3 e 6 entre $H$. brasiliensis e $P$. aquatica e 8 e 16 entre $C$. sinensis e $P$. aquatica de um total de 30 tentativas de cruzamento para cada par de hospedeiros testado (Tab. X). Foi observada a cópula em todos os tratamentos. Nos cruzamentos entre indivíduos oriundos do mesmo hospedeiro (controle) não ocorreram eventos de arrenotoquia exclusiva em nenhum dos três hospedeiros estudados.

\section{DISCUSSÃO}

A variação morfológica observada entre indivíduos de $E$. banksi da mesma população e em diferentes hospedeiros corrobora as observações de Muma et al. (1953), Pritchard \& BAKER (1955) e FleChTMANN \& BAKER (1975) em relação à variação no comprimento das setas dorsais numa mesma população e entre populações de diferentes hospedeiros. A determinação desta variação por esses autores se deu através da análise visual do padrão corporal e de medições isoladas de séries de indivíduos de hospedeiros e origem geográfica diferentes, contudo não foram publicadas medidas que pudessem ser confrontadas no presente trabalho. Desenhos dos tarsos e das tíbias diferiam nesses trabalhos, mas a quetotaxia das pernas não foi informada. 
Tabela X. Ocorrência de prole nos cruzamentos (OPC) e número total e porcentagem de eventos arrenótocos exclusivos (EAE) em três gerações consecutivas de intercruzamentos de indivíduos de E. banksi oriundos dos hospedeiros $\mathrm{H}$. brasiliensis (HE). C. sinensis (CI) e $P$. aquatica (PA). BOD a $28 \pm 1{ }^{\circ} \mathrm{C}$ e 12 horas de fotofase; $70 \pm 10 \%$ UR.

\begin{tabular}{|c|c|c|c|c|c|c|c|}
\hline \multirow{3}{*}{$\begin{array}{l}\text { Origem do } \\
\text { Indivíduo }\end{array}$} & \multirow{3}{*}{$\mathrm{n}$} & \multicolumn{6}{|c|}{ Gerações } \\
\hline & & \multicolumn{2}{|c|}{$\mathrm{F} 1$} & \multicolumn{2}{|c|}{$\mathrm{F} 2$} & \multicolumn{2}{|c|}{$\mathrm{F} 3$} \\
\hline & & $\mathrm{EAE}$ & OPC & EAE & OPC & $\mathrm{EAE}$ & OPC \\
\hline $\mathrm{HE} \times \mathrm{Cl}$ & 15 & 6 & 11 & 8 & 10 & 0 & 0 \\
\hline $\mathrm{Cl} \times \mathrm{HE}$ & 15 & 7 & 15 & 0 & 15 & 0 & 15 \\
\hline $\mathrm{HE} \times \mathrm{PA}$ & 15 & 2 & 12 & 1 & 10 & 1 & 8 \\
\hline $\mathrm{PA} \times \mathrm{HE}$ & 15 & 4 & 15 & 1 & 15 & 0 & 15 \\
\hline $\mathrm{Cl} \times \mathrm{PA}$ & 15 & 9 & 13 & 0 & 0 & 0 & 0 \\
\hline $\mathrm{PA} \times \mathrm{Cl}$ & 15 & 7 & 9 & 1 & 1 & 0 & 0 \\
\hline Totais & 90 & 35 & 75 & 11 & 51 & 1 & 38 \\
\hline Arrenotoquia (\%) & & 46,7 & & 21,6 & & 2,6 & \\
\hline
\end{tabular}

Segundo Pritchard \& Baker (1955), as setas dorsais da fêmea de E. banksi são todas curtas e espatuladas na série típica, com as setas histerossomais dorsolaterais $c 2, d 2$ e $e 2$ maiores do que as dorsocentrais ( $c 1, d 1, e 1$ e $h 1)$. Esse padrão foi observado em nossos estudos para todos os espécimes analisados, ainda que variações no tamanho dessas setas tenham sido encontradas como indicativo de variação intra e interpopulacional.

A variabilidade total encontrada a partir dos estudos morfométricos parece aumentar com o aumento do número de indivíduos e quando são comparadas populações de hospedeiros diferentes e isoladas geograficamente, podendo estar subestimada devido ao pequeno número de indivíduos e de hospedeiros analisados de diferentes países. Através do presente estudo, foi possível demonstrar que os caracteres de maior peso na variação morfológica de $E$. banksi, capazes de individualizar morfologicamente uma população, são o comprimento das setas dorsais, correspondendo à maior parte da variação encontrada, seguido pelas distâncias entre a base dessas setas e, só então, o tamanho do corpo (comprimento e largura do idiossoma). A análise dos 29 caracteres selecionados para todos os espécimes ora estudados certamente resultaria numa melhor interpretação da variação total existente. Essa afirmação é suportada pela grande variação intra-populacional no comprimento das setas dorsais, caráter mais contemplado no presente estudo, que prejudica a análise entre as populações. Por outro lado, as distâncias entre as bases das setas dorsais mostraram-se muito eficientes na separação morfológica entre indivíduos das diferentes localidades (Fig. 19), o que se deveu à homogeneidade intra-populacional do caráter e à conservação da variação entre as populações. Até mesmo fêmeas de populações do mesmo hospedeiro, isoladas geograficamente, conservaram o padrão para esse caráter. Curi- osamente, nas análises de box plot (Figs 9-16) e AVC (Fig. 19) para o mesmo conjunto de dados referentes às distâncias entre elementos dos pares de setas, observamos que a sensibilidade da AVC é indispensável para a discriminação das populações. Enquanto que na análise de box plot não foram registradas diferenças significativas entre as distâncias entre as setas das fêmeas oriundas de C. sinensis e P. aquatica, a AVC separa completamente as populações não só destes hospedeiros entre si mas também entre as populações oriundas do mesmo hospedeiro.

Observamos que o tempo de preservação não prejudicou a análise dos caracteres comprimento e largura do corpo para as populações analisadas como advertiu ReEse et al. (1996), uma vez que não encontramos diferenças significativas nesses caracteres para a maioria das populações (Figs 7 e 8). Contudo, esses caracteres foram responsáveis por explicar a maioria da variação nas populações de $P$. aquatica nas canônicas 1 e 2 e de H. brasiliensis na canônica 1 (Tab. II). Esses resultados poderiam ser apontados como comprometedores da análise. No entanto, nessas populações todos os espécimes foram montados com intervalo de poucos meses, através da mesma técnica, com o mesmo meio de Hoyer e pela mesma pessoa. Isso reduziu a influência de fatores como o método e o tempo de preservação na alteração das dimensões dos exemplares.

Fêmeas oriundas de $H$. brasiliensis de São José do Rio Preto são menores que as fêmeas das outras populações estudadas (Figs 7 e 8) e apresentaram padrão de distância entre setas semelhante ao das fêmeas de $H$. brasiliensis de Cedral (Figs 1-3). Estas, por sua vez, não diferiram das fêmeas das outras duas populações quanto ao tamanho do corpo, o que pode indicar que a redução observada nas fêmeas de São José do Rio Preto seja resultado de um polimorfismo posterior à separação dessas populações possivelmente oriundas de $H$. brasiliensis ou, simplesmente, da redução do tamanho do corpo condicionada pela grande densidade populacional na criação-estoque. Dentre as populações dos três hospedeiros criadas para este estudo, apenas naquela oriunda de $H$. brasiliensis a densidade populacional esteve sempre alta, devido à maior fecundidade das fêmeas (Tab. VI). Ainda nas fêmeas de $H$. brasiliensis de São José do Rio Preto foram registradas distâncias menores entre as setas $s c 2$ e $c 3, c 2$ e $c 1, c 1$ e $d 1, d 2$ e $d 1, d 1$ e $e 1$, até em relação às fêmeas do mesmo hospedeiro de outras localidades. Contudo, esse fato não implica na mudança de padrão e sim na redução proporcional das distâncias entre setas devido à redução do tamanho do corpo (Figs 9 e 13-16). Através de estudos de campo, Aкімоv et al. (2004) analisaram a variação morfológica sazonal do ácaro parasita Varroa destructor (Anderson e Trueman, 2000) (Varroidae) através de morfometria multivariada e observaram que entre os caracteres de maior variação morfológica da população estudada estavam duas medidas de distâncias entre setas. Segundo os autores, essa variação deveu-se à seleção diferencial sazonal dos genótipos que determinaram a diferença significativa no tamanho do corpo entre as amostras coletadas no verão e inverno. Da mesma forma, o observado não foi uma mudança no padrão e, sim, a redução 
proporcional das distâncias entre setas devido à redução do tamanho do corpo. A redução do tamanho do corpo em fêmeas criadas em laboratório por gerações sucessivas foi observada para barbeiros (e.g., Szumlewicz 1976, Zeledón 1981). Assim como nestas populações, os espécimes medidos foram criados em condições laboratoriais por sucessivas gerações e a densidade populacional nas criações esteve sempre alta. Segundo DujARDin et al. (1999), nestas condições, pela grande necessidade nutricional das fêmeas e pela maior sobrevivência dos indivíduos menores da população, esta poderia sofrer uma conseqüente redução no tamanho do corpo nas gerações seguintes devido à reprodução diferencial dos genótipos menores e mais bem sucedidos. Desta forma, acreditamos que a redução do tamanho do corpo verificada nessa população tenha sido condicionada pelo ambiente, ainda que apenas a análise molecular das populações desse hospedeiro poderia apontar a presença ou ausência de um polimorfismo associado ao fenótipo apresentado.

BARBOSA et al. (2004) demonstraram que a fecundidade (expressa em número de ovos/fêmea) não diferiu para os hospedeiros Carica papaya Linnaeus (mamão) e Malpighia emarginata A. DC. (acerola), embora ambas tenham diferido de Citrus sp. (laranja lima) $(37,5 \pm 6,22 ; 31,0 \pm 5,1$ e $11,9 \pm 2,21$, respectivamente). Demonstraram também que a longevidade de E. banksi não diferiu entre estes hospedeiros (aproximadamente 13 dias). Encontramos diferença significativa na longevidade e fecundidade das fêmeas de $E$. banksi entre os hospedeiros $H$. brasiliensis, $C$. sinensis e $P$. aquatica (Tab. VI). Mesmo a longevidade em Citrus $s p$. e C. sinensis diferiu do encontrado por aqueles autores. Como BARBosa et al. (2004) utilizaram nos seus experimentos exemplares da mesma população, provenientes de C. papaya, a longevidade e a sobrevivência podem ter sido subestimadas, uma vez que também encontramos reduções significativas na longevidade e sobrevivência dos ácaros sobre hospedeiros diferentes daqueles em que foram obtidos. Como partimos de diferentes populações obtidas em seus diferentes hospedeiros, acreditamos que os dados relativos a esses parâmetros não sejam comparáveis. Já a fecundidade de $E$. banksi mostrou-se intimamente relacionada com o hospedeiro utilizado nos dois estudos. Ainda no sentido de enriquecer o conhecimento acerca da espécie, integrando os estudos existentes, pudemos perceber que a capacidade de utilização de substratos vegetais diferentes do hospedeiro de origem, para a população oriunda de C. papaya e para a população oriunda de $P$. aquatica, faz de $E$. banksi uma espécie comprovadamente polífaga.

Através dos estudos morfológicos e biológicos foi possível inferir uma possível seqüência de colonização e adaptação de $E$. banksi nos hospedeiros ora estudados. Eutetranychus banksi provavelmente sofreu diferenciação através do isolamento reprodutivo em diferentes hospedeiros, conservando maior distância morfológica e biológica entre $C$. sinensis, hospedeira de uma população inicial na colonização da espécie na área de estudo contemplada, e P. aquatica, espécie possivelmente colonizada a partir de uma população que apresentava fluxo gênico com a população oriunda de $H$. brasiliensis. Essa afirmação é suportada pela capacidade de intercruzamento entre as populações provenientes de $H$. brasiliensis e $P$. aquatica e a maior semelhança morfológica destas em relação à de $C$. sinensis. As diferenças registradas entre os ciclos de vida dessas duas populações podem estar relacionadas à recente colonização de $P$. aquatica e, consequentemente, ao desempenho reprodutivo inferior nesse hospedeiro. Fêmeas coletadas e criadas sobre $P$. aquatica apresentaram taxa de oviposição inferior a daquelas criadas em folhas de $C$. sinensis e $H$. brasiliensis, sob as mesmas condições experimentais. Segundo KASSEN (2002), populações especializadas têm melhor desempenho no seu hospedeiro de origem do que em outros. Fry (1989) demonstrou a habilidade de tetraniquídeos de adaptarem-se a uma nova espécie hospedeira em menos de dez gerações.

As populações coletadas em $H$. brasiliensis, por sua vez, apresentaram grande desempenho no seu hospedeiro natural e incapacidade de utilização de outras espécies vegetais como hospedeiro alternativo. Segundo Agrawal (2002), o desempenho dos tetraniquídeos está geneticamente associado com a preferência e a complexidade das defesas da planta hospedeira e pode restringir a utilização pelo fitófago para uma única espécie. A adaptação dessas populações à $H$. brasiliensis pode ter suplantado a resposta induzida pela sua fitofagia aumentando seu desempenho, mas diminuindo a capacidade de utilização de novas espécies vegetais.

Segundo Kassen (2002), populações especializadas têm melhor desempenho no seu hospedeiro de origem e isso pode resultar numa restrição do fluxo gênico entre as populações nos diferentes hospedeiros mesmo em condições de ocorrência simpátrica (e.g., FilchaK et al. 2000, Groman \& Pellmyr 2000). O isolamento reprodutivo entre populações provenientes de $C$. sinensis e $P$. aquatica provavelmente estabeleceu-se devido à seqüência adaptativa possivelmente ocorrida; primeiro entre as populações de $C$. sinensis com o novo hospedeiro, $H$. brasiliensis, seguida pela colonização de populações de $H$. brasiliensis em $P$. aquatica. A isso soma-se a rápida diferenciação sofrida pelos ácaros pelo seu modo de reprodução haplodiplóide, que diminui a variabilidade genética intrapopulacional e ao mesmo tempo aumenta a diferença entre as populações (Helle \& OvermeEr 1973). Então, considerando a polifagia e a ampla distribuição geográfica, é esperado que novas linhagens possam ser freqüentemente descobertas.

Em nossos experimentos constatamos que eventos de partenogênese arrenótoca exclusiva não ocorreram nas populações de E. banksi em seu próprio hospedeiro, ocorrendo somente quando as populações dos diferentes hospedeiros são intercruzadas ou submetidas a outros substratos. Assim como Helle \& Pieterse (1965) observamos grande incompatibilidade reprodutiva entre indivíduos provenientes de diferentes hospedeiros, com drástica redução da produção de prole e, provavelmente, a esterilidade dos híbridos, sendo que as populações encontradas sobre $C$. sinensis e $P$. aquatica parecem ser reprodutivamente isoladas entre si. 
Contudo, mais estudos poderiam ser desenvolvidos acerca de E. banksi uma vez que pode se tratar de um complexo de espécies. A análise molecular seria uma ferramenta importante a ser utilizada na tentativa de diferenciá-las, desde que acompanhada de estudos complementares das informações biológicas. NAvAJAs et al. (1999) encontraram diferenças significativas entre populações de Amphitetranychus viennensis (Zacher, 1920) oriundas da França e do Japão através do seqüenciamento do DNA ribossomal nuclear e parte do gene mitocondrial (regiões ITS2 e COI, respectivamente). Entretanto, houve fertilidade das fêmeas híbridas indicando a coespecificidade dessas populações.

A ocorrência de polimorfismos em E. banksi pôde ser constatada não apenas pela variação no tamanho do corpo e setas e distância das setas dorsais do idiossoma, mas também no número das setas táteis dos fêmures I e II e das tíbias III e IV (Tab. IV). A diferença relevante no entendimento desses polimorfismos é que o primeiro se correlaciona com os hospedeiros, presumivelmente devido à restrição do fluxo gênico condicionado ao hábito alimentar e o segundo não se correlaciona, sugerindo que sua presença nas diferentes populações se deva ao fluxo gênico entre elas. A variação do número das setas táteis no fêmur II e na tíbia IV representaram caracteres importantes na variação intra-populacional compartilhada nas seis populações estudadas e não foram correlacionadas com o hospedeiro utilizado por elas. A variação no número das setas táteis das pernas ocorrendo na forma de mosaicos nas diferentes populações, ou seja, presentes em populações que poderiam manter o fluxo gênico entre si, e também nas quais esse fluxo apresentou-se restrito (e.g., populações oriundas de $C$. sinensis e $P$. aquatica do município de São José do Rio Preto) podem indicar o compartilhamento genético destas de uma forma indireta. Acreditamos que E. banksi possa reunir populações em processo evolutivo de adaptação a diferentes hospedeiros, além da provável manutenção do fluxo gênico entre populações de diferentes locais e hospedeiros. Assim, uma "redescrição" ao nível específico como por exemplo para as populações oriundas de C. sinensis resultaria numa visão restrita e errônea da espécie, ainda que embasada no isolamento reprodutivo das populações oriundas de $C$. sinensis e $P$. aquatica e na distinção morfológica destas em relação às de $H$. brasiliensis e $P$. aquatica através de caracteres morfológicos (comprimento das setas v2, sc2, c1, c2, c3 e e1). Apesar disso, o fluxo gênico entre elas seria possível através das populações oriundas de $H$. brasiliensis. Através desta análise, conclui-se que o fluxo gênico pode ser constante, ainda que haja fenótipos distintos em dados hospedeiros e até se estabeleçam isolamento reprodutivo entre certas populações, mas não com outras. Neste caso, seria possível apenas a busca de variedades ecológicas ou subespécies (Futuyma 1992), mas este propósito poderia não ter uma aplicabilidade legítima, ainda que muitas das populações - dentre as registradas nas 23 famílias vegetais relatadas na literatura como hospedeiras desta espécie - pudessem apresentar diferenças e mesmo particularidades morfológicas e no ciclo de vida entre si.

\section{AGRADECIMENTOS}

A Carlos H.W. Flechtmann e ao Setor de Zoologia Agrícola, ESALQ/USP de Piracicaba pelo empréstimo de exemplares de E. banksi das coleções e valiosas sugestões ao manuscrito. A Manoel G.C. Gondim Jr e ao Departamento de Agronomia, Universidade Federal Rural de Pernambuco, Área de Fitossanidade, pela doação de espécimes. A Fernando R. de Carvalho, Programa de Pós-graduação em Biologia Animal, pelo treinamento no uso do Programa SAS ${ }^{\circledR}$. À Denise N.M. Ferreira e Vera C. Silva pela leitura crítica do primeiro manuscrito. À Empresa Athena Mudas Ltda, pela concessão de bolsa parcial à primeira autora. Ao CNPq pela concessão de bolsa ao segundo autor.

\section{LITERATURA CITADA}

AттіAн, H.H. 1967. The Genus Eutetranychus in U.A.R., with description of three new species. Bulletin de la Société Entomologique d'Egypte 51: 11-16.

AgraWAL, A.A. 2002. Host-range evolution: adaptation and tradeoffs in fitness of mites on alternative hosts. Ecology 81 (2): 500-508.

Akimov, I.A.; S.V. Benedyk \& L.M. Zaloznaya. 2004. Complex analysis of morphological characters of Gamasid mite Varroa destructor (Parasitiformes, Varroidae). Vestnik Zoologii 38 (5): 57-66.

Baker, E.W. \& D.M. TutTle. 1994. A guide to the spider mites (Tetranychidae) of the United States. West Blomfield, Indira Publishing House, 347p.

Barbosa, D.G.F.; M.G.C. Gondim Jr; R. Barros; J.V. de Oliveira \& F.R. DA SiLva. 2004. Biologia Comparada de Eutetranychus banksi (McGregor) (Acari: Tetranychidae) em fruteiras tropicais. Neotropical Entomology 33 (4): 403-406.

Bellini, M.R.; G.J. De Morais \& R.J.F. Feres. 2005. Ácaros (Acari) de dois sistemas de cultivo de seringueira no noroeste do estado de São Paulo. Neotropical Entomology 34 (3): 475-484.

Berlocher, S.H. \& J.L. Feder. 2002. Sympatric speciation in phytophagous insects: moving beyond controversy? Annual Review of Entomology 47: 773-815.

Bolland, H.R.; J. Gutierrez \& C.H.W. Flechtmann. 1998. World Catalogue of the Spider mite Family (Acari: Tetranychidae). Leiden, Brill, 392p.

Childers, C.C.; M.M. Abou-Setta \& M.S. Nawar. 1991. Biology of Eutetranychus banksi: Life tables on "Marsh" grapefruit leave at different temperatures (Acari: Tetranychidae). International Journal Acarology 17: 29-35.

Dean, H.A.1980. Population differences of Texas citrus mites on leaves of four orange varieties in Texas. Journal of Economic Entomology 73: 813-816.

Dujardim, J.P.; M. Steindel; T. Chavez; M. Machane \& C.J. Schofield 1999. Changes in the sexual dimorphism of Triatominae in the transition from natural to artificial habitats. Memórias do Instituto Oswaldo Cruz 94 (4): 565-569.

Feres, R.J.F.; D.C. Rossa-Feres; R.D. Daud \& R.S. Santos. 2002. 
Diversidade de ácaros (Acari, Arachnida) em seringueiras (Hevea brasiliensis Muell. Arg., Euphorbiaceae) na região noroeste do Estado de São Paulo, Brasil. Revista Brasileira de Zoologia 19 (1): 137-144.

FilchaK, K.E.; J.B. Roethele \& J.L. Feder. 2000. Natural selection and sympatric divergence in the apple maggot Rhagoletis pomonella. Nature 407: 739-742.

Flechtmann, C.H.W. 1975. Elementos de Acarologia. São Paulo, Nobel, 344p.

Flechtmann, C.H.W. \& J.M. Abreu. 1973. Ácaros fitófagos do estado da Bahia, Brasil (Notas Preliminares). Ciência e Cultura 25: $244-251$.

Flechtmann, C.H.W. \& E.W. Baker. 1975. A report on the Tetranychidae (Acari) of Brazil. Revista Brasileira de Entomologia 19 (3): 111-122.

Funk, D. J.; K.E. FilchaK \& J.L. Feder. 2002. Herbivorous insects: model systems for the comparative study of speciation. Genetica 116: 251-267.

Futuyma, D.J. 1992. Biologia Evolutiva. Ribeirão Preto, Sociedade Brasileira de Genética/CNPq, 646p.

FrY, J.D. 1989. Evolutionary adaptation to host plants in a laboratory population of the phytophagous mite Tetranychus urticae Koch. Oecologia 81: 559-565.

Gondim Jr, M.G.C. \& J.V. Oliveira. 2001. Ácaros de fruteiras tropicais: importância econômica, identificação e controle, p. 317-355. In: S.J. Michereff \& R. Barros (Eds.). Proteção de plantas na agricultura sustentável. Recife, Universidade Federal Rural de Pernambuco, 400p.

GrandJEAn, F. 1939. Les segments post-larvaires de l'hystérosoma chez les Oribates (Acariens). Bulletin de la Société Zoologique de France 64: 273-284.

Groman, J.D. \& O. Pellmyr. 2000. Rapid evolution and specialization following host colonization in a yucca moth. Journal of Evolutionary Biology 13: 223-236.

Helle, W. \& W.P.J. Overmeer. 1973. Variability in tetranychid mites. Annual Review of Entomology 18: 97-120.

Helle, W. \& A.H. Pieterse. 1965. Genetic affinities between adjacent populations of spider mites (Tetranychus urticae Koch.). Entomologia Experimentalis et Applicata 8: 305-308.

Jeppson, L.R.; H.H. KeIfer \& E.W. BaKer. 1975. Mites injurious to economic plants. Berkeley, University of California, 641p.

Kassen, R. 2002. The experimental evolution of specialists, generalists, and the maintenance of diversity. Journal of Evolutionary Biology 15 (2): 173-190.
LINDQUisT, E.E. 1985. Anatomy, phylogeny and systematics, p. 3-28. In: W. Helle \& M.W. Sabelis (Eds). Spider mites, their biology, natural enemies and control. Amsterdam, Elsevier, World Crop Pests, 800p.

McGregor, E.A. 1914. Four new tetranychids. Annals Entomological Society of America 7: 354-360.

Migeon, A. \& F. Dorkeld. 2006. Spider Mites Web: A comprehensive database for the Tetranychidae. Available online at: http://www.montpellier.inra.fr/CBGP/spmweb/

notespecies.php?id = 327 [Accessed: 21/XII/2007]

Monteiro, L.R. \& S.F. Reis. 1999. Princípios de morfometria geométrica. Ribeirão Preto, Holos, 198p.

Moraes, G.J. de \& C.H.W. Flechtmann. 2008. Manual de acarologia: acarologia básica e ácaros de plantas cultivadas no Brasil. Ribeirão Preto, Holos, 288p.

Muma, M.H.; H. Holtzberg \& R.M. Pratt. 1953. Eutetranychus banksi (McGregor) recentely found on citrus in Florida (Acarina: Tetranychidae). Florida Entomologist 36: 141-142.

Navajas, M.; J. Gutierrez; J. Lagnel; G. Fauvel \& T. Gotoh. 1999. DNA sequences and cross-breeding experiments in the hawthorn spider mite Amphitetranychus viennensis reveal high genetic differentiation between Japanese and French populations. Entomologia Experimentalis et Applicata 90 (2): 113-122.

Pritchard, E.A. \& E.W. BAKer. 1955. A revision of the spider mite family Tetranychidae. San Francisco, Pacific Coast Entomological Society, Memoirs Series, 472p.

Reese, N.E.; W.M. Boyce; I.A. Gardner \& D.M. Nelson. 1996. Fixation affects morphometric characters of Psoropes cuneli mites (Acari: Psoroptidae). Journal of Medical Entomology 33 (5): 835-838.

Reyment, R.A.; R.E. Blackith \& N.A. CAmpbell. 1981. Multivariate morphometrics. New York, Academic Press, 233p.

SkorackA, A.; L. KuCZynSKI \& W. Magowski. 2002. Morphological variation in different host populations of Abacarus hystrix (Acari: Prostigmata: Eriophyoidea). Experimental and Applied Acarology 26: 187-193.

Szumlewicz, A.P. 1976. Laboratory colonies of Triatominae, biology and population dynamics, p. 63-82. In: American Trypanosomiasis Research. Washington, PAHO Scientific Publication, 318p.

ZeLEDón, R. 1981. El Triatoma dimidiata y su Relación con la Enfermedad de Chagas. Costa Rica, Editorial EUNED, 146p.

Submitted: 12.XII.2008; Accepted: 15.IX.2009.

Editorial responsibility: Pedro Gnaspini Netto 